\title{
Dissection of two soybean QTL conferring partial resistance to Phytophthora sojae through sequence and gene expression analysis
}

Hehe Wang ${ }^{1}$, Asela Wijeratne ${ }^{2}$, Saranga Wijeratne ${ }^{2}$, Sungwoo Lee ${ }^{3}$, Christopher G Taylor ${ }^{1}$, Steven K St. Martin ${ }^{3}$, Leah $\mathrm{MCHale}^{3}$ and Anne E Dorrance ${ }^{1 *}$

\begin{abstract}
Background: Phytophthora sojae is the primary pathogen of soybeans that are grown on poorly drained soils. Race-specific resistance to $P$. sojae in soybean is gene-for-gene, although in many areas of the US and worldwide there are populations that have adapted to the most commonly deployed resistance to P. sojae (Rps) genes. Hence, this system has received increased attention towards identifying mechanisms and molecular markers associated with partial resistance to this pathogen. Several quantitative trait loci (QTL) have been identified in the soybean cultivar 'Conrad' that contributes to the expression of partial resistance to multiple $P$. sojae isolates.

Results: In this study, two of the Conrad QTL on chromosome 19 were dissected through sequence and expression analysis of genes in both resistant (Conrad) and susceptible ('Sloan') genotypes. There were 1025 single nucleotide polymorphisms (SNPs) in 87 of 153 genes sequenced from Conrad and Sloan. There were 304 SNPs in 54 genes sequenced from Conrad compared to those from both Sloan and Williams 82, of which 11 genes had SNPs unique to Conrad. Eleven of 19 genes in these regions analyzed with qRT-PCR had significant differences in fold change of transcript abundance in response to infection with P. sojae in lines with QTL haplotype from the resistant parent compared to those with the susceptible parent haplotype. From these, 8 of the 11 genes had SNPs in the upstream, untranslated region, exon, intron, and/or downstream region. These 11 candidate genes encode proteins potentially involved in signal transduction, hormone-mediated pathways, plant cell structural modification, ubiquitination, and basal resistance.
\end{abstract}

Conclusions: These findings may indicate a complex defense network with multiple mechanisms underlying these two soybean QTL conferring resistance to $P$. sojae. SNP markers derived from these candidate genes can contribute to fine mapping of QTL and marker assisted breeding for resistance to $P$. sojae.

Keywords: QTL, Gene expression, Sequencing, SNP, Soybean, P. sojae, qRT-PCR

\section{Background}

Phytophthora sojae Kaufm. and Gerd. is a yield limiting soil borne pathogen of soybean (Glycine max L. Merr.). This disease is most prevalent for soybean grown in poorly drained soils, and symptoms include pre- and post-emergence damping-off, root and stem rot, yellowing and wilting of lower leaves of the plants [1,2]. P. sojae is characterized as a hemi-biotrophic pathogen. P. sojae

\footnotetext{
* Correspondence: dorrance.1@osu.edu

${ }^{1}$ The Department of Plant Pathology, The Ohio State University, Wooster $\mathrm{OH}$ 44691, USA

Full list of author information is available at the end of the article
}

haustoria are produced during the early intracellular biotrophic stage and as the pathogen colonizes root tissues. At later stages of infection, light tan to brown symptoms develop leading to necrosis and cell death. Resistance to $P$. sojae in soybean is conferred by both single, dominant genes, known as Rps genes, that confer resistance to specific pathotypes (races) and partial resistance which is inherited as quantitative trait loci (QTL) [1,2]. In both types of resistance, zoospores move to the roots where they encyst, germinate, and penetrate within the first six hours after inoculation (hai) [3-5]. In Rps mediated resistance, the hyphae from avirulent $P$. sojae strains were 
only found in the first three cell layers. In partial resistance, hyphae colonized deeper into the cells of the root cortex. At 48 hai, hyphae were found in the same layers of root cells for soybean genotypes that are highly susceptible or had high levels of partial resistance [4]. The visible haustoria observed at 48 hai, and disease symptoms at 72 hai, suggested that the biotrophic stage of $P$. sojae occurred within the first 48 hai and the necrotrophic stage may begin approximately 72 hai in both partial resistant and susceptible soybean genotypes [4].

A total of 19 QTL have been identified in soybean genotypes resistant to $P$. sojae, of which 15 were mapped from eight separate populations from the resistant cultivar 'Conrad' [6-13]. Of these 15 QTLs, six mapped to chromosome (Chr.) 2 (formerly Molecular Linkage Group D1b; MLG D1b), five mapped to Chr. 13 (MLG F), two mapped to Chr. 18 (MLG G), and the remaining two mapped to Chr. 19 (MLG L) [6-8,10-12]. Interestingly, the QTL on Chr. 2 and 13 were not consistently detected with multiple isolates or the different field assays from these studies $[7,8]$. Individual QTL that respond differentially to specific isolates of a pathogen and environmental conditions have also been identified in several other host-pathosystems [14-17]. In order to breed for a broad-spectrum durable host resistance, the selected QTL must be able to confer resistance to multiple isolates of a pathogen, act stably under different environment conditions, explain a large percentage of the phenotypic variation (major-effect QTL), and be confirmed in different mapping populations [15]. In an earlier study, one of the QTL on Chr. 18 and two of the QTL on Chr. 19 responded similarly following inoculation to three isolates of $P$. sojae and with two different disease assay methods [11]. These three QTL also explained a significant proportion of phenotypic variation that contributed to reduced levels of root rot and lesion size. Additionally, RILs with the resistant haplotypes at these QTL had significantly higher yield than RILs with the susceptible haplotypes in field tests. These attributes make these QTL strong potential targets for breeding of broad-spectrum resistance in soybean against $P$. sojae.

To improve the efficiency of incorporating these QTL into cultivar development, identifying the key genes controlling these QTL and characterizing their functions is key [15]. These genes are not only the best markers for efficient breeding, but they are also important in understanding the mechanisms that contribute to the expression of partial resistance which still remained largely unknown. In the soybean-P. sojae interaction, few studies have explored the molecular mechanisms that contribute to the expression of partial resistance in Conrad to P. sojae. Pathogenesis-related (PR) protein PR1a, PR2, basic peroxidase and matrix metalloproteinase transcript levels were reported to be higher in Conrad compared to OX 20-8 (highly susceptible) 3 days after inoculation (dai) [18]. Two studies reported that preformed suberin, a component of basal resistance, was higher in whole roots of Conrad compared to those of the susceptible line OX760-6 [5,19]. This was proposed to contribute to a 2-3 h delay in $P$. sojae penetration through the epidermis of Conrad compared to the susceptible line. Whole-genome transcription profiling of eight soybean genotypes with differential levels of partial resistance to $P$. sojae, were analyzed using soybean Affymetrix ${ }^{\circledR}$ gene chips [10,20-22]. The eight soybean genotypes were examined at 3 and 5 dai, and 25,000 genes had statistically significant responses to infection, with little difference in transcript levels between these two sampling time points $[20,22]$. The infection response of four soybean genotypes, including Conrad and a susceptible cultivar Sloan, was also analyzed in a time course assay at several locations surrounding lesion development with the Affymetrix ${ }^{\circledR}$ gene chips $[10,21]$. Approximately 20,000 genes (53.4\%) had significant changes in transcript abundance in Conrad and Sloan compared to mock inoculated controls in response to $P$. sojae infection, and the majority of changes occurred at 2, 3, and 5 dai [10]. Under the two QTL on Chr. 19, 76.0\% of the genes had significant infection response in Conrad or Sloan from this microarray analysis [10] (Figure 1). Interestingly, most of the annotated functions of the genes from these regions have been reported to be involved in host defense to plant pathogens. None of the genes in this region have an $R$ gene-like motif based on the Williams 82 reference genome [23].

To date, only three genes have been cloned from disease resistance QTL in plants and they each encode proteins with diverse functions [24-28], which is in accordance with the multiple hypotheses for mechanisms underlying QTL in effectively limiting pathogen colonization [16]. These three genes all had sequence variation between the resistance and susceptible alleles [25-27]. In this study, our hypotheses were that i) a complex network of defense-pathways is underlying each soybean QTL conferring resistance to $P$. sojae; ii) sequence of the genes under a QTL between resistant and susceptible genotypes are different in regions that will affect gene expression; and iii) sequence analysis will expedite the identification of potential candidate genes in soybean conferring resistance to P. sojae.

The two QTL on Chr. 19 responded similarly across different phenotypic assays and isolates of $P$. sojae, and a large number of defense genes associated with these QTL had significant changes in transcript abundance in response to $P$. sojae infection. Thus, they are prime candidates to explore the variation in gene sequence and 


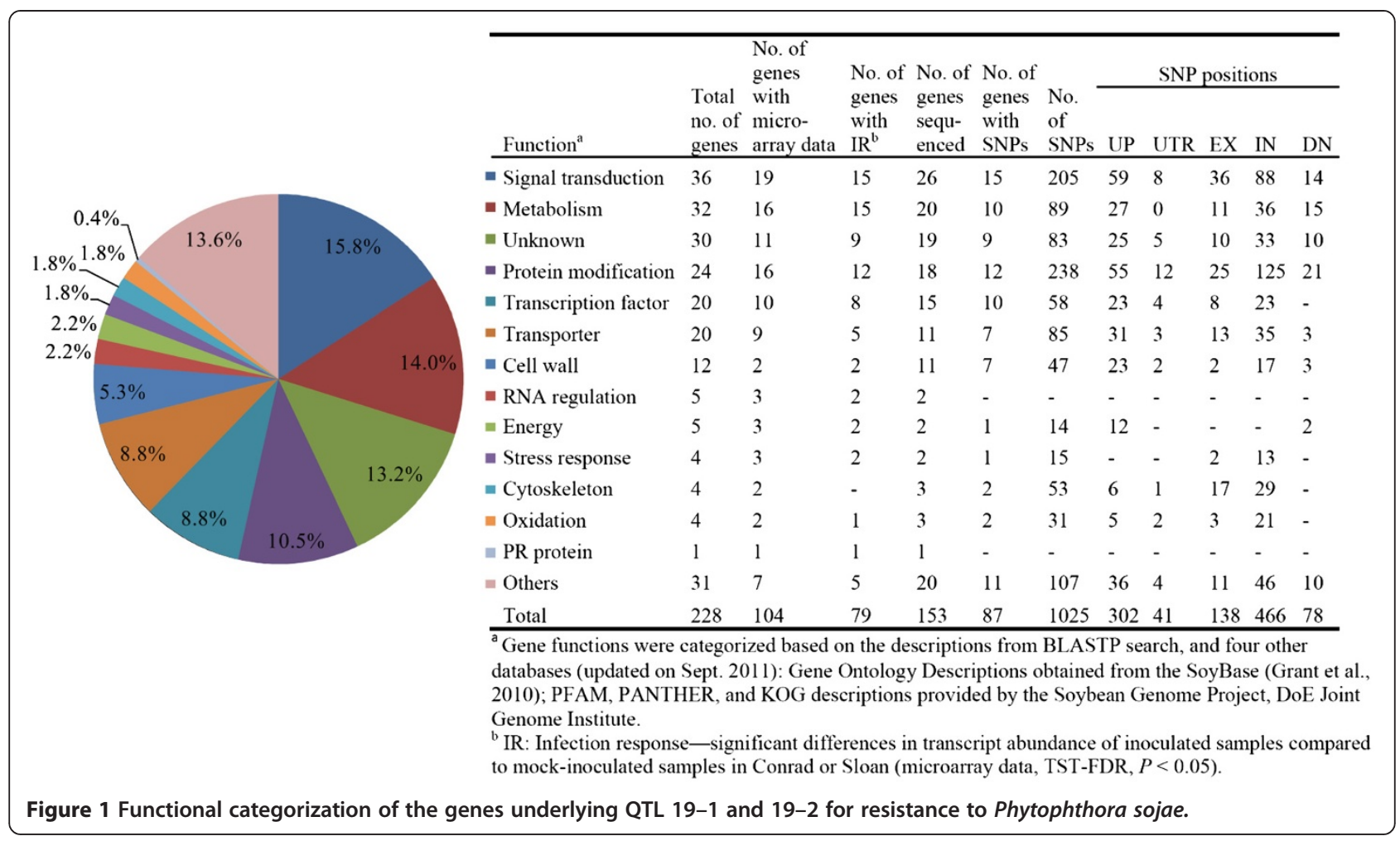

expression patterns between the resistant and susceptible genotypes. Therefore, our objectives were to: i) confirm the QTL in an advanced and larger $F_{6: 8}$ Conrad $\times$ Sloan population (246 RILs); ii) examine the sequence variation of the genes underlying these QTL between Conrad and Sloan; iii) analyze the expression patterns of candidate genes representing different defense mechanisms underlying these QTL following infection by $P$. sojae. This research will not only address an expedited means to identify candidate genes in soybean conferring resistance to $P$. sojae, but also provide more polymorphic markers for further fine mapping of the QTL regions.

\section{Results and discussion}

\section{QTL confirmation in $\mathrm{F}_{6: 8}$ population}

These two QTL were identified previously in the $\mathrm{F}_{4: 6}$ Conrad $\times$ Sloan population of 186 RILs $[10,11]$. In tray test assays carried out in the present study, best linear unbiased predictor (BLUP) values [29] from root lesion lengths measured at 7 dai from $P$. sojae isolate 1.S.1.1 in the Conrad $\times$ Sloan $\mathrm{F}_{6: 8}$ RIL population ranged from -12.9 to 12.7 (lesion length 21.5 to $51.9 \mathrm{~mm}$ ) with a normal distribution, indicating that the resistance was quantitatively inherited (Figure 2). The broad-sense heritability estimate for lesion length was 0.87 . Conrad has high levels of partial resistance to $P$. sojae and Sloan is moderately susceptible. Both of cultivars performed consistently as checks across replicates.
Hereafter, Conrad and Sloan will be referred to as the $\mathrm{R}$ and $\mathrm{S}$ genotypes, respectively. Five QTL with resistance alleles from R cultivar, two each on Chr. 18 and 19 and one on Chr. 1 (MLG D1A), were identified, each explaining $6.0-19.6 \%$ of the phenotypic variation for a total of $67.2 \%$ for interval mapping (IM), and $4.8-11.9 \%$ of the phenotypic variation for a total of $37.1 \%$ for composite interval mapping (CIM) (Table 1$)$.

The QTL 18-2, 19-1, and 19-2, which confer resistance to multiple $P$. sojae isolates, were first mapped in a Conrad $\times$ Sloan $\mathrm{F}_{4: 6}$ population using two different phenotypic methods $[10,11]$. In this study, all three QTL were confirmed in the larger $\mathrm{F}_{6: 8}$ generation, flanked by

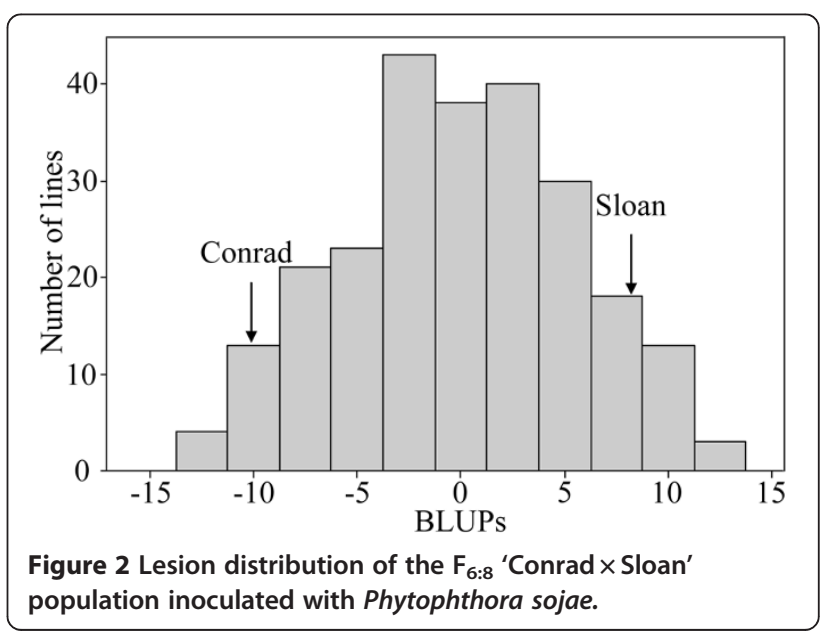


Table 1 QTL from Conrad against Phytophthora sojae mapped using the $\mathrm{F}_{6: 8}$ Conrad $\times$ Sloan population

\begin{tabular}{|c|c|c|c|c|c|c|c|c|c|c|c|}
\hline \multirow[t]{2}{*}{$\mathrm{QTL}^{\mathrm{a}}$} & \multicolumn{2}{|l|}{ IM } & \multicolumn{2}{|l|}{ CIM } & \multirow[t]{2}{*}{ Marker } & \multicolumn{6}{|c|}{ Selected lines for qRT-PCR ${ }^{c}$} \\
\hline & LOD & Exp. Var. (\%) & LOD & Exp. Var. (\%) & & $\mathbf{R}$ & 2022 & 1960 & 1974 & 1854 & $S$ \\
\hline \multirow[t]{5}{*}{$19-1$} & 6.0 & 11.8 & 3.5 & 4.8 & BARC-047496-12943 & + & + & + & - & - & - \\
\hline & & & & & Satt527 & + & + & + & - & - & - \\
\hline & & & & & Glyma19g35340 & + & + & + & - & - & - \\
\hline & & & & & GML_OSU10 & + & + & + & - & - & - \\
\hline & & & & & BARCSOYSSR_19_1243 & + & + & + & - & - & - \\
\hline \multirow[t]{18}{*}{$19-2$} & 9.4 & 18.1 & 7.9 & 11.9 & Glyma19g40800 & + & + & + & - & - & - \\
\hline & & & & & BARCSOYSSR_19_1452 ${ }^{d}$ & + & + & + & - & - & - \\
\hline & & & & & Glyma19g40940 & + & + & + & - & - & - \\
\hline & & & & & Glyma19g41210 & + & + & + & - & - & - \\
\hline & & & & & Glyma19g41390 & + & + & + & - & - & - \\
\hline & & & & & BARCSOYSSR_19_1473 & + & + & + & - & - & - \\
\hline & & & & & Glyma19g41580 & + & + & + & - & - & - \\
\hline & & & & & Glyma19g41780 & + & + & + & - & - & - \\
\hline & & & & & Glyma19g41800 & + & + & + & - & - & - \\
\hline & & & & & Glyma19g41870 & + & + & + & - & - & - \\
\hline & & & & & Glyma19g41900 & + & + & + & - & - & - \\
\hline & & & & & Glyma19g42120 & + & + & + & - & - & - \\
\hline & & & & & Glyma19g42200 & + & + & + & - & - & - \\
\hline & & & & & Glyma19g42220 & + & + & + & - & - & - \\
\hline & & & & & Glyma19g42240 & + & + & + & - & - & - \\
\hline & & & & & Glyma19g42340 & + & + & + & - & - & - \\
\hline & & & & & Glyma19g42390 & + & + & + & - & - & - \\
\hline & & & & & BARC-039977-07624 & + & + & + & - & - & - \\
\hline \multirow[t]{3}{*}{1} & 3.1 & 6.0 & 3.7 & 5.0 & BARC-060037-16311 & + & + & - & + & - & - \\
\hline & & & & & BARC-064441-18673 & + & + & - & + & - & - \\
\hline & & & & & BARC-054071-12319 & + & + & - & + & - & - \\
\hline \multirow[t]{2}{*}{$18-1$} & 5.3 & 11.7 & 4.5 & 6.1 & BARCSOYSSR_18_1707 & + & - & - & + & + & - \\
\hline & & & & & BARCSOYSSR_18_1710 & + & - & - & + & + & - \\
\hline \multirow[t]{4}{*}{$18-2$} & 10.5 & 19.6 & 8.4 & 9.3 & BARCSOYSSR_18_1777 & + & - & - & + & + & - \\
\hline & & & & & BARC-057845-14952 & + & - & - & + & + & - \\
\hline & & & & & BARC-039397-07314 & + & - & - & + & + & - \\
\hline & & & & & BARCSOYSSR_18_1949 & + & - & - & + & + & - \\
\hline
\end{tabular}

The QTL presence in the six selected lines for GRT-PCR is also shown.

${ }^{a}$ QTL were presented as chromosome number, followed by the serial number if there were more than one on the same chromosome;

b Markers tested in each QTL interval: markers started with 'BARC' or 'Sat' are from the public databases (Choi et al., 2007; Hyten et al., 2010; Song et al., 2010), and markers started with 'Glyma' are the PAMSA markers designed in this study;

"Conrad (R) alleles for each marker were presented as " + " in the selected lines for qRT-PCR, while "-" referred to the Sloan (S) alleles;

${ }^{\mathrm{d}}$ Nearest marker under each QTL interval.

similar markers as in the $\mathrm{F}_{4: 6}$ population. The QTL 18-2 (Gm18: 59016134 to 62263273 ) co-localized with the position of the $R$-gene mediated resistance to $P$. sojae, Rps4 (flanked by markers BARC-031121-06998 and BARC-031193-07008, Gm18: 60469824 to 60780954) and Rps6 (flanked by markers Sat_372 and BARC017669-03102, Gm18: 61095646 to 62046327) [30-32]. Residual function of defeated $R$-genes has been proposed to contribute to the expression of partial resistance in other host-pathogen systems [16]. However, the R genotype in this study does not have known Rps genes, nor does this locus have isolate specificity to $P$. sojae. Direct sequencing of this QTL region would be necessary to assess if $R$-gene-like sequences were present in $\mathrm{R}$ or $\mathrm{S}$ genotypes. In contrast to QTL $18-2$, there were no $R$ gene-like sequences in Williams 82 where the QTL 19-1 
and 19-2 mapped, which indicates the mechanisms underlying these two QTL that contribute to the expression of partial resistance are likely to be different than $R$ gene mediated resistance. The QTL 19-1 and 19-2 spanned $\sim 4.0 \mathrm{cM}$ and $\sim 4.8 \mathrm{cM}$, respectively, on the soybean consensus map v4.0 [33]. In this study, these two QTL had the log of odds likelihood LOD scores of 3.5 and 7.9 (CIM), and accounted for 4.8 and $11.9 \%$ of the variation in lesion length, respectively (Table 1 ). The expression of broad-spectrum resistance to multiple isolates, consistent detection through different phenotypic assays, and detection in two generations of the same population, make the two QTL on Chr. 19 prime targets to examine the genetic and mechanistic contributions towards the expression of partial resistance to $P$. sojae in soybean. These QTL regions are large and encompass many genes, thus, numerous molecular markers per locus may be required to ensure successful introgression of the critical component(s) of the locus for full expression of resistance in cultivars.

\section{Sequence variation of genes underlying the QTL between $\mathrm{R}$ and $\mathrm{S}$ cultivars}

The QTL 19-1 and 19-2 spanned 0.5 Mb (Gm19: 42819782 to 43332226$)$ and 1.5 Mb (Gm19: 47108989 to 48606553), respectively, on the physical map [23]. A total of 53 and 175 genes were within QTL 19-1 and 19-2, respectively (Additional files 1 and 2). These genes were classified into 14 functional categories (Figure 1). Of these 228 genes, 11 from QTL $19-1$ and 142 from QTL 19-2 were successfully amplified in R and S genotypes with LR-PCR and sequenced with Illumina GA II, including $1.2 \mathrm{~kb}$ upstream and $400 \mathrm{bp}$ downstream of the gene coding regions. A total of 1025 single nucleotide polymorphisms (SNPs) were identified between $\mathrm{R}$ and $S$ in 87 genes (nine genes from QTL 19-1 and 76 from QTL 19-2) (Figures 1 and 3, Additional file 3). The 'Transcription factor' (10 of the 15 genes) and 'Protein modification' (12 of the 18 genes) functional groups had the highest percentage of genes with SNPs between $\mathrm{R}$ and $\mathrm{S}$ (Figure 1). Of the 79 genes with significant infection response in $\mathrm{R}$ or $\mathrm{S}$ from the previous microarray studies [10,21], 53 were successfully sequenced and 414 SNPs were identified from 29 genes (55\% of sequenced genes). For comparison, 17 of the 25 genes with no infection response from the microarray results were sequenced and 154 SNPs were identified from 10 genes (59\% of sequenced genes).

Among these sequences, there was a greater number of SNPs in the introns and $1.2 \mathrm{~kb}$ upstream regions compared to the exons and UTRs (Figure 1). This was expected and similar to that observed in the soybean genome reported from other studies [34]. There was an average of 1.6 single nucleotide polymorphisms (SNPs)

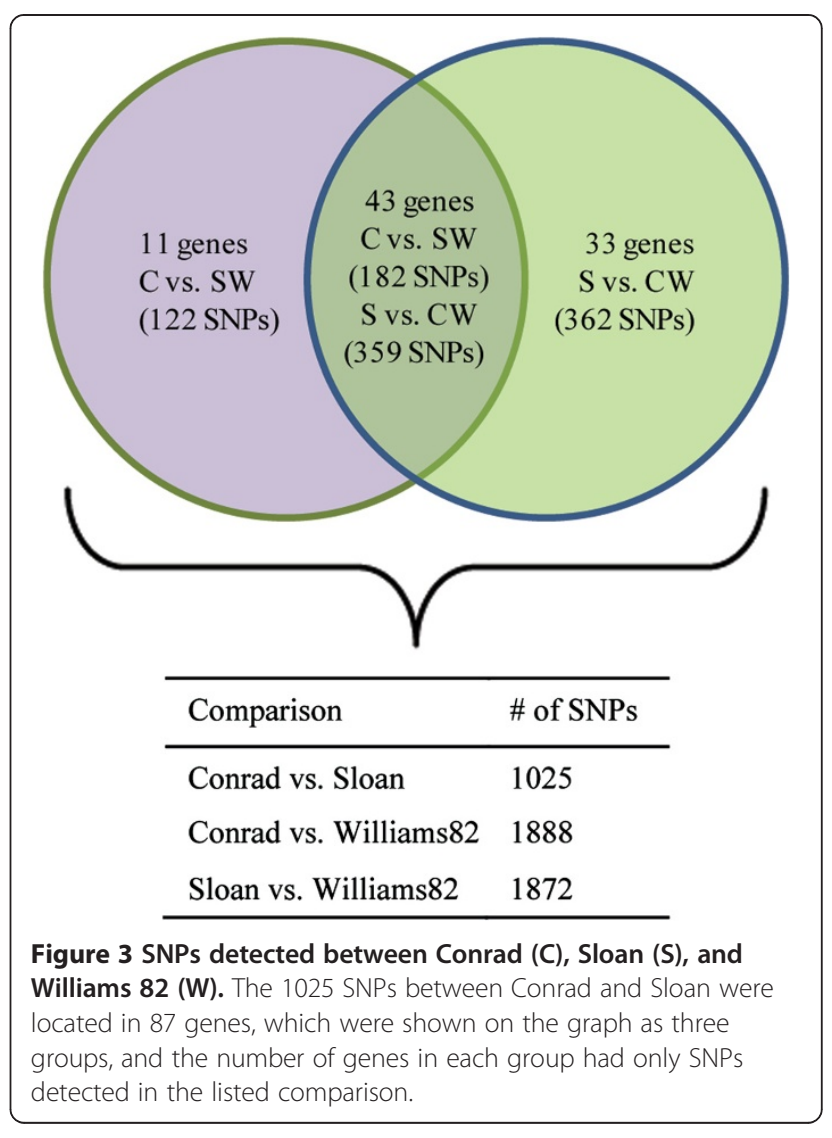

per 1000 bp (0.16\%), which was slightly higher than the average SNP frequency (1 SNP per $1000 \mathrm{bp}$ ) in the genic and perigenic regions of soybean cultivars calculated from previous studies [35,36]. Marker assays using the 1,536 SNPs from the "Universal Soy Linkage Panel", estimated an average of 458 SNPs for each pair of soybean cultivars based on pair wise comparisons of 96 elite cultivars [33]. Only 320 of the 1536 SNPs were polymorphic between the $\mathrm{R}$ and $\mathrm{S}$ genotypes, which indicated that the polymorphism between $\mathrm{R}$ and $\mathrm{S}$ was slightly lower than the average for pairs of soybean cultivars [Cregan and Dorrance, unpublished data]. Thus, an elevated SNP frequency in the genic and perigenic regions of defense-related genes may reflect the sequence differences in these regions that control the phenotypic differences in resistance between $\mathrm{R}$ and $\mathrm{S}$.

Of the total 1025 SNPs between $\mathrm{R}$ and S, 304 SNPs located in 54 genes within QTL 19-2 occurred in R compared to both $\mathrm{S}$ and Williams 82 (Figure 3). There were 11 genes that had 122 SNPs unique in $\mathrm{R}$ when compared to $\mathrm{S}$ and Williams 82 (Figure 3, Table 2). Both $\mathrm{S}$ and Williams 82 have lower levels of partial resistance than R, hence we hypothesized that these 304 SNPs, especially those in the 11 genes, are more likely to contribute to the expression of high levels of partial resistance. Of these 304 SNPs, 21 were non-synonymous, located in 
Table 2 Eleven genes in which Conrad had unique SNPs vs. Sloan \& Williams82

\begin{tabular}{|c|c|c|c|c|c|c|c|c|c|c|c|}
\hline GlymaID/Affy ID ${ }^{a}$ & PFAM $^{\mathbf{b}}$ & GO function ${ }^{c}$ & PANTHER $^{d}$ & $\mathrm{KOG}^{\mathrm{e}}$ & BLASTP & E-value & $\begin{array}{l}\text { BLAST } \\
\text { hit species }\end{array}$ & $\begin{array}{l}\text { \# of } \\
\text { SNPs }\end{array}$ & SNP locations & $\mathrm{IR}_{-}^{\mathrm{f}} \mathrm{C}$ & IR_S \\
\hline Glyma19g40800/- & $\begin{array}{l}\text { WD domain, } \\
\text { G-beta repeat }\end{array}$ & - & $\begin{array}{l}\text { WD repeat } \\
\text { protein }\end{array}$ & $\begin{array}{l}\text { WD-repeat protein } \\
\text { WDR6, WD } \\
\text { repeat superfamily }\end{array}$ & $\begin{array}{l}\text { Transducin/WD40 } \\
\text { domain-containing } \\
\text { protein }\end{array}$ & $\mathrm{OE}+00$ & $\begin{array}{l}\text { Arabidopsis } \\
\text { thaliana }\end{array}$ & 47 & $\begin{array}{l}\text { exon, intron, } \\
\text { downstream }\end{array}$ & & \\
\hline Glyma19g40840/- & $\begin{array}{l}\text { Pectinesterase/ } \\
\text { Plant invertase/ } \\
\text { pectin methylesterase } \\
\text { inhibitor }\end{array}$ & $\begin{array}{l}\text { Pectinesterase activity; } \\
\text { cell wall; cell wall } \\
\text { modification }\end{array}$ & - & - & $\begin{array}{l}\text { Pectinesterase; } \\
\text { Pectinesterase } \\
\text { inhibitor }\end{array}$ & $\mathrm{OE}+00$ & $\begin{array}{l}\text { Medicago } \\
\text { truncatula }\end{array}$ & 1 & downstream & & \\
\hline Glyma19g40940/- & $\begin{array}{l}\text { Glycosyl hydrolases } \\
\text { family } 28\end{array}$ & $\begin{array}{l}\text { Carbohydrate metabolism; } \\
\text { polygalacturonase activity }\end{array}$ & - & - & $\begin{array}{l}\text { Glycoside hydrolase } \\
\text { family } 28 \text { protein }\end{array}$ & $\mathrm{OE}+00$ & $\begin{array}{l}\text { Arabidopsis } \\
\text { thaliana }\end{array}$ & 2 & upstream, intron & & \\
\hline $\begin{array}{l}\text { Glyma19g41590/ } \\
\text { Gma.14131.1.S1_at } \\
\text { GmaAffx.26456.1.S1_at } \\
\text { GmaAffx.76884.1.S1_at }\end{array}$ & $\begin{array}{l}\text { Haloacid } \\
\text { dehalogenase-like } \\
\text { hydrolase|Redoxin| } \\
\text { NHL repeat }\end{array}$ & Hydrolase activity & $\begin{array}{l}\text { 2-deoxyglucose-6- } \\
\text { phosphate } \\
\text { phosphatase } 2\end{array}$ & $\begin{array}{l}\text { Predicted haloacid- } \\
\text { halidohydrolase } \\
\text { and related } \\
\text { hydrolases }\end{array}$ & $\begin{array}{l}\text { 2-deoxyglucose-6- } \\
\text { phosphate } \\
\text { phosphatase, } \\
\text { putative }\end{array}$ & $\mathrm{OE}+00$ & $\begin{array}{l}\text { Ricinus } \\
\text { communis }\end{array}$ & 1 & intron & - & - \\
\hline Glyma19g41900/- & F-box domain & - & - & - & $\begin{array}{l}\text { Phloem-specific } \\
\text { lectin PP2-like } \\
\text { protein }\end{array}$ & $2 \mathrm{E}-82$ & $\begin{array}{l}\text { Arabidopsis } \\
\text { thaliana }\end{array}$ & 8 & $\begin{array}{l}\text { upstream, } \\
\text { 5' UTR, exon, } \\
\text { downstream }\end{array}$ & & \\
\hline $\begin{array}{l}\text { Glyma19g42120/ } \\
\text { Gma.14232.1.S1_at }\end{array}$ & - & - & - & $\begin{array}{l}\text { Uncharacterized } \\
\text { conserved protein }\end{array}$ & $\begin{array}{l}\text { heparan-alpha- } \\
\text { glucosaminide } \\
\text { N-acetyltransferase }\end{array}$ & $0+00$ & $\begin{array}{l}\text { Arabidopsis } \\
\text { thaliana }\end{array}$ & 1 & intron & $-2,-3$ & $-2,-3,-5$ \\
\hline $\begin{array}{l}\text { Glyma19g42200/ } \\
\text { Gma.9498.1.S1_a_at }\end{array}$ & $\begin{array}{l}\text { Rapid ALkalinization } \\
\text { Factor (RALF) }\end{array}$ & Signal transducer activity & - & - & $\begin{array}{l}\text { Rapid ALkalinization } \\
\text { Factor }\end{array}$ & $9 e-47$ & $\begin{array}{l}\text { Medicago } \\
\text { truncatula }\end{array}$ & 11 & $\begin{array}{l}\text { upstream, } \\
\text { intron }\end{array}$ & 2 & - \\
\hline $\begin{array}{l}\text { Glyma19g42210/ } \\
\text { GmaAffx.69813.1.A1_at }\end{array}$ & RAD9 & DNA repair & $\begin{array}{l}\text { DNA repair } \\
\text { protein RAD9 }\end{array}$ & $\begin{array}{l}\text { Checkpoint 9-1-1 } \\
\text { complex, RAD9 } \\
\text { component }\end{array}$ & Rad9 & $\mathrm{OE}+00$ & $\begin{array}{l}\text { Medicago } \\
\text { truncatula }\end{array}$ & 12 & $\begin{array}{l}\text { upstream, } \\
\text { exon, intron }\end{array}$ & - & - \\
\hline $\begin{array}{l}\text { Glyma19g42220/ } \\
\text { GmaAffx.33386.1.A1_at }\end{array}$ & $\begin{array}{l}\text { Respiratory burst } \\
\text { NADPH oxidase; } \\
\text { EF hand; Ferric } \\
\text { reductase like } \\
\text { transmembrane } \\
\text { component; } \\
\text { FAD-binding } \\
\text { domain; Ferric } \\
\text { reductase NAD } \\
\text { binding domain }\end{array}$ & $\begin{array}{l}\text { Calcium ion binding iron } \\
\text { ion binding oxidoreductase } \\
\text { activity; FAD binding }\end{array}$ & NADPH oxidase & $\begin{array}{l}\text { Ferric reductase, } \\
\mathrm{NADH} / \mathrm{NADPH} \\
\text { oxidase and } \\
\text { related proteins }\end{array}$ & $\begin{array}{l}\text { Respiratory burst } \\
\text { oxidase } 2\end{array}$ & $0 \mathrm{E}+00$ & $\begin{array}{l}\text { Medicago } \\
\text { truncatula }\end{array}$ & 29 & $\begin{array}{l}\text { upstream, } \\
\text { exon, intron }\end{array}$ & 2 & 2 \\
\hline
\end{tabular}


Table 2 Eleven genes in which Conrad had unique SNPs vs. Sloan \& Williams82 (Continued)

\begin{tabular}{|c|c|c|c|c|c|c|c|c|c|c|c|}
\hline $\begin{array}{l}\text { Glyma19g42240/ } \\
\text { Gma.13144.1.S1_at }\end{array}$ & $\begin{array}{l}\text { Core histone } \\
\mathrm{H} 2 \mathrm{~A} / \mathrm{H} 2 \mathrm{~B} / \mathrm{H} 3 / \mathrm{H} 4 \text {; } \\
\text { Histone-like } \\
\text { transcription factor } \\
\text { (CBF/NF-Y) and } \\
\text { archaeal histone }\end{array}$ & DNA binding & Histone $\mathrm{H} 2 \mathrm{~A}$ & Histone 2A & Histone H2A 7 & $2 e-73$ & $\begin{array}{l}\text { Arabidopsis } \\
\text { thaliana }\end{array}$ & 2 & $\begin{array}{l}\text { upstream, } \\
\text { 5' UTR }\end{array}$ & $-2,5$ & 3,5 \\
\hline Glyma19g42390/- & $\begin{array}{l}\text { Cyclin, } \\
\text { N-terminal domain }\end{array}$ & - & $\begin{array}{l}\text { Family not } \\
\text { named }\end{array}$ & Cyclin & $\begin{array}{l}\text { Cyclin-dependent } \\
\text { protein kinase, } \\
\text { putative }\end{array}$ & $6 e-59$ & $\begin{array}{l}\text { Ricinus } \\
\text { communis }\end{array}$ & 8 & $\begin{array}{l}\text { upstream, } \\
\text { intron, } \\
\text { downstream }\end{array}$ & & \\
\hline
\end{tabular}

a GlymalD/Affymetrix probe IDs that match with the predicted genes underlying QTL (http://soybase.org/AffyChip/), where "-" means there was no Affymetrix IDs available for the specific gene; b PFAM description provided by the Soybean Genome Project, DoE Joint Genome Institute ( http://www.phytozome.net/soybean.php, updated on July 2011);

' Gene Ontology Descriptions obtained from the (http://soybase.org, updated on July 2011);

d PANTHER description provided by the Soybean Genome Project, DoE Joint Genome Institute (http://www.phytozome.net/soybean.php, updated on July 2011):

${ }^{\text {e }}$ KOG Description assigned by the Soybean Genome Project, DoE Joint Genome Institute (http://www.phytozome.net/soybean.php, updated on July 2011);

${ }^{f}$ IR: Infection response-significant differences in transcript abundance of inoculated samples compared to mock-inoculated samples in Conrad (C) or Sloan (S) (microarray data, TST-FDR, $P<0.05$ ) at specified time

points (dai); where "-" means there was no significant response observed at any time point after inoculation, a positive value indicates that the gene was up-regulated at the specified time point, and a negative value

indicates the gene was down-regulated at the specified time point $[10,21]$. 
Table 3 SNPs causing non-synonymous changes in Conrad (C) genes compared to Sloan (S) and Williams82 (W)

\begin{tabular}{|c|c|c|c|c|c|c|c|c|c|c|c|c|}
\hline \multirow[t]{2}{*}{ GlymaID/Affy ID ${ }^{a}$} & \multirow[t]{2}{*}{ PFAM $^{\mathbf{b}}$} & \multirow[t]{2}{*}{ GO function ${ }^{c}$} & \multirow[t]{2}{*}{ PANTHER $^{d}$} & \multirow[t]{2}{*}{ KOG $^{\mathrm{e}}$} & \multirow[t]{2}{*}{ BLASTP function } & \multirow{2}{*}{ E-value } & \multirow{2}{*}{$\begin{array}{l}\text { BLAST } \\
\text { hit species }\end{array}$} & \multirow{2}{*}{ SNP position ${ }^{f}$} & \multicolumn{2}{|c|}{ Amino acid } & \multicolumn{2}{|l|}{$I^{g}$} \\
\hline & & & & & & & & & $\bar{C}$ & SW & $\mathrm{C}$ & $\mathrm{S}$ \\
\hline \multirow[t]{10}{*}{ Glyma19g40800/ } & \multirow[t]{10}{*}{ WD domain, G-beta repeat } & & \multirow[t]{10}{*}{ WD repeat protein } & \multirow{10}{*}{$\begin{array}{l}\text { WD-repeat protein } \\
\text { WDR6, WD repeat } \\
\text { superfamily }\end{array}$} & \multirow{10}{*}{$\begin{array}{l}\text { Transducin/WD40 } \\
\text { domain-containing } \\
\text { protein }\end{array}$} & \multirow{10}{*}{$0 \mathrm{E}+00$} & \multirow{10}{*}{$\begin{array}{l}\text { Arabidopsis } \\
\text { thaliana }\end{array}$} & 47113947 & V & M & & \\
\hline & & & & & & & & 47116418 & L & V & & \\
\hline & & & & & & & & 47116517 & $\mathrm{~T}$ & A & & \\
\hline & & & & & & & & 47116586 & । & V & & \\
\hline & & & & & & & & 47116637 & G & $\mathrm{R}$ & & \\
\hline & & & & & & & & 47118102 & G & $\mathrm{D}$ & & \\
\hline & & & & & & & & 47118156 & $\mathrm{~N}$ & S & & \\
\hline & & & & & & & & 47118234 & s & L & & \\
\hline & & & & & & & & 47118485 & Y & $\mathrm{H}$ & & \\
\hline & & & & & & & & 47119034 & V & I & & \\
\hline Glyma19g41230/- & POT family & $\begin{array}{l}\text { Oligopeptide transport; } \\
\text { membrane; transporter } \\
\text { activity }\end{array}$ & $\begin{array}{l}\text { Oligopeptide } \\
\text { transporter-related }\end{array}$ & $\begin{array}{l}\text { H+/oligopeptide } \\
\text { symporter }\end{array}$ & $\begin{array}{l}\text { Nitrate transporter, } \\
\text { putative }\end{array}$ & $0 \mathrm{E}+00$ & $\begin{array}{l}\text { Ricinus } \\
\text { communi }\end{array}$ & 47535046 & Q & K & & \\
\hline $\begin{array}{l}\text { Glyma19g41630/ } \\
\text { GmaAffx.82770.1.S1_at }\end{array}$ & $\begin{array}{l}\text { Nicotianamine } \\
\text { synthase protein }\end{array}$ & $\begin{array}{l}\text { Nicotianamine synthase } \\
\text { activity }\end{array}$ & - & - & $\begin{array}{l}\text { Nicotianamine } \\
\text { synthase }\end{array}$ & $2 \mathrm{E}-177$ & $\begin{array}{l}\text { Lotus } \\
\text { japonicus }\end{array}$ & 47867334 & $\mathrm{R}$ & K & $-3,-5$ & $-3,-5$ \\
\hline \multirow[t]{2}{*}{ Glyma19g41740/- } & $\begin{array}{l}\text { Calmodulin } \\
\text { binding protein-like }\end{array}$ & Calmodulin binding & - & - & $\begin{array}{l}\text { Calmodulin-binding } \\
\text { protein, putative }\end{array}$ & $2 \mathrm{E}-50$ & Oryza sativa & 47939823 & $\mathrm{~S}$ & A & & \\
\hline & & & & & & & & 47940855 & L & M & & \\
\hline \multirow[t]{2}{*}{$\begin{array}{l}\text { Glyma19g41800/ } \\
\text { GmaAffx.67321.1.S1_at }\end{array}$} & \multirow[t]{2}{*}{$\begin{array}{l}\text { Kinesin motor } \\
\text { domain }\end{array}$} & \multirow{2}{*}{$\begin{array}{l}\text { ATPase activity } \\
\text { microtubule binding } \\
\text { microtubule motor } \\
\text { activity }\end{array}$} & \multirow[t]{2}{*}{ Kinesin heavy chain } & \multirow[t]{2}{*}{$\begin{array}{l}\text { Kinesin } \\
\text { (KAR3 subfamily) }\end{array}$} & \multirow[t]{2}{*}{$\begin{array}{l}\text { Kinesin heavy chain, } \\
\text { putative }\end{array}$} & $0 \mathrm{E}+00$ & $\begin{array}{l}\text { Ricinus } \\
\text { communis }\end{array}$ & 47974179 & M & K & - & - \\
\hline & & & & & & & & 47974243 & $\mathrm{~N}$ & K & & \\
\hline
\end{tabular}




\section{Table 3 SNPs causing non-synonymous changes in Conrad (C) genes compared to Sloan (S) and Williams82 (W) (Continued)}

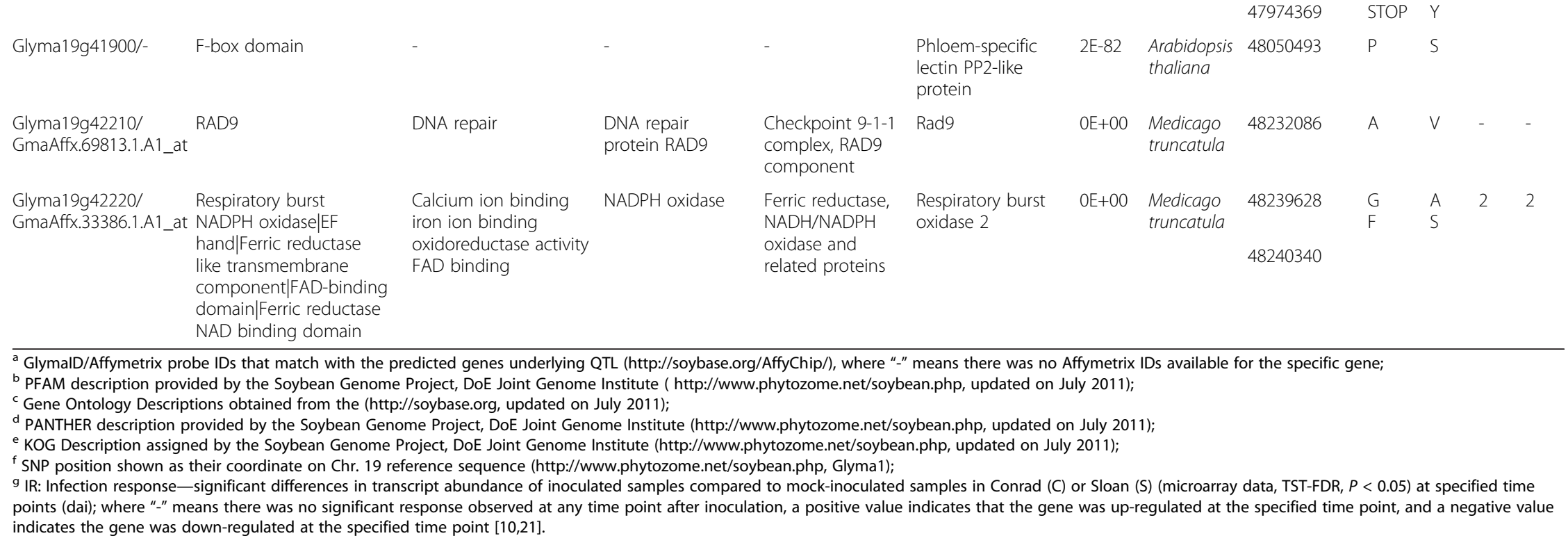




\begin{tabular}{|c|c|c|c|c|c|c|c|c|c|c|c|c|c|}
\hline \multirow[t]{2}{*}{ GlymaID } & \multirow[t]{2}{*}{ PFAM $^{a}$} & \multirow[t]{2}{*}{ GO function ${ }^{b}$} & \multirow[t]{2}{*}{ PANTHER $^{c}$} & \multirow[t]{2}{*}{$\mathrm{KOG}^{\mathrm{d}}$} & \multirow[t]{2}{*}{ BLASTP } & \multirow[t]{2}{*}{ E-value } & \multirow{2}{*}{$\begin{array}{l}\text { BLAST hit } \\
\text { species }\end{array}$} & \multirow[t]{2}{*}{ Contrasts } & \multicolumn{5}{|c|}{ Sampling points (hai) } \\
\hline & & & & & & & & & 12 & 24 & 48 & $72 I^{\mathrm{h}}$ & $72 \_U^{i}$ \\
\hline \multirow{3}{*}{ Glyma19g35340 } & \multirow{3}{*}{$\begin{array}{l}\text { Zinc-binding } \\
\text { dehydrogenase }\end{array}$} & \multirow[t]{3}{*}{ Zinc ion binding } & \multirow{3}{*}{$\begin{array}{l}\text { Alcohol } \\
\text { dehydrogenase } \\
\text { related }\end{array}$} & \multirow{3}{*}{$\begin{array}{l}\text { Alcohol } \\
\text { dehydrogenase, } \\
\text { class III }\end{array}$} & \multirow{3}{*}{$\begin{array}{l}\text { Alcohol } \\
\text { dehydrogenase, } \\
\text { putative }\end{array}$} & \multirow[t]{3}{*}{$0 \mathrm{E}+00$} & \multirow{3}{*}{$\begin{array}{l}\text { Ricinus } \\
\text { communis }\end{array}$} & $\mathrm{CC}^{\mathrm{e}}$ & & & & -1.8 & \\
\hline & & & & & & & & $\mathrm{RC}^{\mathrm{f}}$ & & & & 2.0 & \\
\hline & & & & & & & & $\mathrm{IC}^{\mathrm{g}}$ & & & -1.5 & & \\
\hline \multirow{3}{*}{ Glyma19g40800 } & \multirow{3}{*}{$\begin{array}{l}\text { WD domain, } \\
\text { G-beta repeat }\end{array}$} & \multirow[t]{3}{*}{-} & \multirow[t]{3}{*}{ WD repeat protein } & \multirow{3}{*}{$\begin{array}{l}\text { WD-repeat } \\
\text { protein WDR6, } \\
\text { WD repeat } \\
\text { superfamily }\end{array}$} & \multirow{3}{*}{$\begin{array}{l}\text { Transducin/WD40 } \\
\text { domain-containing } \\
\text { protein }\end{array}$} & \multirow[t]{3}{*}{$0 \mathrm{E}+00$} & \multirow{3}{*}{$\begin{array}{l}\text { Arabidopsis } \\
\text { thaliana }\end{array}$} & $\mathrm{CC}$ & & & & -2.4 & \\
\hline & & & & & & & & $\mathrm{RC}$ & & & & 2.4 & \\
\hline & & & & & & & & IC & & & & & -1.9 \\
\hline Glyma19g40940 & Glycosyl hydrolases & Carbohydrate & - & - & Glycoside hydrolase & $\mathrm{OE}+00$ & Arabidopsis & $\mathrm{CC}$ & & & & & 1.7 \\
\hline & & $\begin{array}{l}\text { metabolism; } \\
\text { polygalacturonase }\end{array}$ & & & & & & $\mathrm{RC}$ & & & -1.9 & -1.6 & \\
\hline & & activity & & & & & & IC & & & -2.2 & & \\
\hline Glyma19g40950 & WRKY DNA & Transcription factor & - & - & Putative WRKY & $9 \mathrm{E}-91$ & Arabidopsis & $\mathrm{CC}$ & & & & -1.7 & \\
\hline & & $\begin{array}{l}\text { activity; sequence- } \\
\text { specific DNA binding }\end{array}$ & & & $\begin{array}{l}\text { transcription } \\
\text { factor } 42\end{array}$ & & & $\mathrm{RC}$ & & & & 2.0 & \\
\hline & & & & & & & & IC & & & & & \\
\hline Glyma19g40970 & AUX/IAA family & Transcription factor & - & - & Auxin-responsive & $1 \mathrm{E}-48$ & Ricinus & CC & & & & & \\
\hline & & activity & & & $\begin{array}{l}\text { protein IAA20, } \\
\text { putative }\end{array}$ & & communis & $\mathrm{RC}$ & & & & & -2.1 \\
\hline & & & & & & & & IC & & & & & -2.4 \\
\hline Glyma19g41580 & - & - & - & - & Transcription & $1 \mathrm{E}-30$ & Arabidopsis & $\mathrm{CC}$ & & & -2.7 & -7.3 & -3.2 \\
\hline & & & & & & & & $\mathrm{RC}$ & & & 1.5 & 7.3 & 2.5 \\
\hline & & & & & & & & IC & & & -1.9 & & \\
\hline Glyma19g41800 & Kinesin & ATPase activity & Kinesin heavy chain & Kinesin & Kinesin heavy & $\mathrm{OE}+00$ & Ricinus & CC & -7.0 & -6.6 & -9.1 & -6.4 & -3.4 \\
\hline & motor domain & $\begin{array}{l}\text { microtubule binding } \\
\text { microtubule motor }\end{array}$ & & (KAR3 subfamily) & chain, putative & & communis & $\mathrm{RC}$ & & & & 2.0 & \\
\hline & & activity & & & & & & IC & -5.4 & -4.8 & -8.6 & -3.2 & -4.7 \\
\hline Glyma19g41900 & F-box domain & - & - & - & Phloem-specific & $2 \mathrm{E}-82$ & Arabidopsis & $\mathrm{CC}$ & & & & -1.9 & -1.9 \\
\hline & & & & & $\begin{array}{l}\text { lectin PP2-like } \\
\text { protein }\end{array}$ & & & $\mathrm{RC}$ & & & 2.0 & & 1.5 \\
\hline & & & & & & & & IC & 1.8 & & & & \\
\hline Glyma19g41930 & Leucine & Protein binding & F-box/leucine rich & Leucine rich & Ubiquitin-protein & $0 \mathrm{E}+00$ & Ricinus & $C C$ & & & & & \\
\hline & Rich Repeat & & repeat protein & $\begin{array}{l}\text { repeat proteins, } \\
\text { some proteins }\end{array}$ & ligase, putative & & communis & $\mathrm{RC}$ & & & & 3.3 & \\
\hline & & & & contain F-box & & & & IC & & & & & \\
\hline Glyma19g42050 & Calcineurin-like & Protein serine/threonine & Serine/threonine & Serine/threonine & Serine/threonine- & $\mathrm{OE}+00$ & Arabidopsis & $\mathrm{CC}$ & & & & & \\
\hline & & & protein phosphatase & $\begin{array}{l}\text { specific protein } \\
\text { phosphatase PP1, }\end{array}$ & $\begin{array}{l}\text { protein phosphatase } \\
\text { PP1 isozyme } 8\end{array}$ & & thaliana & $\mathrm{RC}$ & & & 1.7 & & \\
\hline & & & & catalytic subunit & & & & IC & & & & & \\
\hline
\end{tabular}


Table 4 Genes with significant expression differences in Conrad vs. Sloan in qRT-PCR (Continued)

Glyma19g42120 -

Glyma19g42200 Rapid ALkalinization Signal transducer activity

Factor (RALF)

$\begin{array}{cl}\text { Glyma19g42220 } & \text { Respiratory burst } \\ & \text { NADPH oxidase; } \\ & \text { EF hand; Ferric } \\ & \text { reductase like } \\ & \text { transmembrane } \\ & \text { component; } \\ & \text { FAD-binding } \\ & \text { domain; Ferric } \\ \text { reductase NAD } & \text { binding domain }\end{array}$

Glyma19g42240 Core histone

$\mathrm{H} 2 \mathrm{~A} / \mathrm{H} 2 \mathrm{~B} / \mathrm{H} 3 / \mathrm{H} 4$;

Histone-like

transcription facto

(CBF/NF-Y) and

archaeal histone

Glyma19g42340 Protein tyrosine kinase

Calcium ion binding iron

ion binding oxidoreductase

activity; FAD binding

NADPH oxidase

Protein-tyrosine kinase activity; protein amino acid phosphorylation;

Glyma19g42460 Core histone $\mathrm{H} 2 \mathrm{~A} / \mathrm{H} 2 \mathrm{~B} / \mathrm{H} 3 / \mathrm{H} 4$ Histone-like transcription factor

(CBF/NF-Y) and archaeal histone ATP binding DNA binding

DNA binding

transcription factor

activity

\section{Uncharacterized \\ heparan-alph}

conserved $p$

glucosaminide

$\mathrm{N}$-acetyltransferase

0+00 Arabidopsis CC

thaliana

$\mathrm{RC}$

Rapid ALkalinization 9e-47 Medicago CC

Factor truncatula

$-3.9$

Ferric reductase,

$\mathrm{NADH} / \mathrm{NADPH}$

Respiratory burst oxidase 2

OE +00 Medicago CC

oxidase and

truncatula $\mathrm{RC}$

related proteins
Histone $\mathrm{H} 2 \mathrm{~A}$

Histone 2A

Histone H2A 7

2e-73

Arabidopsis CC

thaliana $\mathrm{RC}$

IC

Mapkk-related serine/threonine

protein kinases

MEKK and related NPK1-related

serine/threonine protein kinase $1 \mathrm{~L}$

$\mathrm{OE}+00$ Arabidopsis $\mathrm{CC}$ thaliana

$\mathrm{RC}$

Histone-like

transcription factor

CCAAT-binding

ccaat-related

transcription factor

C (HAP5)

$P<0.05$, Fold difference $>1.5$. Empty cell indicates that there was no significant difference, and a negative value indicates the fold that Sloan's expression ratio was greater than Conrad's.

a PFAM description provided by the Soybean Genome Project, DoE Joint Genome Institute (http://www.phytozome.net/soybean.php, updated on July 2011);

${ }^{\mathrm{b}}$ Gene Ontology Descriptions obtained from the (http://soybase.org, updated on July 2011);

c PANTHER description provided by the Soybean Genome Project, DoE Joint Genome Institute (http://www.phytozome.net/soybean.php, updated on July 2011);

${ }^{d}$ KOG Description assigned by the Soybean Genome Project, DoE Joint Genome Institute (http://www.phytozome.net/soybean.php, updated on July 2011);

e CC: Constitutive contrast-significant fold difference in transcript abundance between Conrad and Sloan (C : S) in mock-inoculated samples at specified time points (HAl);

${ }^{\mathrm{f}} \mathrm{RC}$ : Response contrast-significant fold differences in infection response ratios (inoculated / mock-inoculated) in Conrad compared to Sloan (C:S) at specified time points (HAl);

${ }^{9}$ IC: Infection contrast-significant fold difference in transcript abundance between Conrad and Sloan (C : S) in infected samples at specified time points (HAI);

${ }^{\mathrm{h}}$ Samples were collected from the inoculation site at $72 \mathrm{HAl}_{\text {; }}$

i Samples were collected from the front of lesion margin at $72 \mathrm{HAI}$ 
Table 5 Genes with significant expression differences in the $\mathbf{R}$ group vs. $\mathbf{S}$ group in $\mathrm{qRT}-\mathrm{PCR} . \mathrm{P}<0.05$, Fold difference $>1.5$

\begin{tabular}{|c|c|c|c|c|c|c|c|c|c|c|c|c|c|}
\hline \multirow[t]{2}{*}{ GlymalD } & \multirow[t]{2}{*}{ PFAM $^{a}$} & \multirow[t]{2}{*}{ GO function ${ }^{b}$} & \multirow[t]{2}{*}{ PANTHER $^{c}$} & \multirow[t]{2}{*}{$\mathrm{KOG}^{\mathrm{d}}$} & \multirow[t]{2}{*}{ BLASTP } & \multirow[t]{2}{*}{ E-value } & \multirow{2}{*}{$\begin{array}{l}\text { BLAST } \\
\text { hit species }\end{array}$} & \multirow{2}{*}{ Contrasts } & \multicolumn{5}{|c|}{ Sampling points (hai) } \\
\hline & & & & & & & & & 12 & 24 & 48 & $72 I^{\mathrm{h}}$ & $72 \_U^{i}$ \\
\hline \multirow{3}{*}{ Glyma19g35340 } & \multirow{3}{*}{$\begin{array}{l}\text { Zinc-binding } \\
\text { dehydrogenase }\end{array}$} & \multirow[t]{3}{*}{ Zinc ion binding } & \multirow{3}{*}{$\begin{array}{l}\text { Alcohol } \\
\text { dehydrogenase } \\
\text { related }\end{array}$} & \multirow{3}{*}{$\begin{array}{l}\text { Alcohol } \\
\text { dehydrogenase, } \\
\text { class III }\end{array}$} & \multirow{3}{*}{$\begin{array}{l}\text { Alcohol } \\
\text { dehydrogenase, } \\
\text { putative }\end{array}$} & \multirow{3}{*}{$\mathrm{OE}+00$} & \multirow{3}{*}{$\begin{array}{l}\text { Ricinus } \\
\text { communis }\end{array}$} & $\mathrm{CC}^{\mathrm{e}}$ & & & & & \\
\hline & & & & & & & & $R C^{f}$ & & & & 1.5 & \\
\hline & & & & & & & & $I^{g}$ & & & & & \\
\hline \multirow[t]{3}{*}{ Glyma19g40800 } & \multirow{3}{*}{$\begin{array}{l}\text { WD domain, } \\
\text { G-beta repeat }\end{array}$} & \multirow[t]{3}{*}{-} & \multirow[t]{3}{*}{ WD repeat protein } & \multirow{3}{*}{$\begin{array}{l}\text { WD-repeat protein } \\
\text { WDR6, WD } \\
\text { repeat superfamily }\end{array}$} & \multirow{3}{*}{$\begin{array}{l}\text { Transducin/WD40 } \\
\text { domain-containing } \\
\text { protein }\end{array}$} & \multirow[t]{3}{*}{$\mathrm{OE}+00$} & \multirow{3}{*}{$\begin{array}{l}\text { Arabidopsis } \\
\text { thaliana }\end{array}$} & CC & & & & & \\
\hline & & & & & & & & $\mathrm{RC}$ & & & & 1.8 & \\
\hline & & & & & & & & IC & & & & & \\
\hline \multirow[t]{3}{*}{ Glyma19g40940 } & \multirow{3}{*}{$\begin{array}{l}\text { Glycosyl } \\
\text { hydrolases } \\
\text { family } 28\end{array}$} & \multirow{3}{*}{$\begin{array}{l}\text { Carbohydrate metabolism; } \\
\text { polygalacturonase activity }\end{array}$} & \multirow[t]{3}{*}{-} & - & Glycoside hydrolase & $0 \mathrm{E}+00$ & Arabidopsis & CC & & & & & \\
\hline & & & & & family 28 protein & & thaliana & $\mathrm{RC}$ & & & -1.9 & & \\
\hline & & & & & & & & IC & & & -1.6 & & \\
\hline Glyma19g40950 & WRKY DNA & Transcription factor activity; & - & - & Putative WRKY & $9 \mathrm{E}-91$ & Arabidopsis & CC & & & & & \\
\hline & & $\begin{array}{l}\text { sequence-specific } \\
\text { DNA binding }\end{array}$ & & & $\begin{array}{l}\text { transcription } \\
\text { factor } 42\end{array}$ & & & $\mathrm{RC}$ & & & & & \\
\hline & & & & & & & & IC & & & -1.5 & & \\
\hline Glyma19g40970 & AUX/IAA family & Transcription factor activity & - & - & Auxin-responsive & $1 \mathrm{E}-48$ & Ricinus & CC & -1.5 & & & & \\
\hline & & & & & $\begin{array}{l}\text { protein IAA20, } \\
\text { putative }\end{array}$ & & communis & $\mathrm{RC}$ & & & & & -1.9 \\
\hline & & & & & & & & IC & & -2.2 & & & -1.8 \\
\hline Glyma19g41580 & - & - & - & - & Transcription factor & $1 \mathrm{E}-30$ & Arabidopsis & CC & & & -1.6 & -2.8 & \\
\hline & & & & & & & & $\mathrm{RC}$ & & & 1.5 & 2.3 & \\
\hline & & & & & & & & IC & & & & & \\
\hline Glyma19g41780 & GATA zinc finger & Transcription factor activity; & Transcription & - & GATA transcription & $1 \mathrm{E}-23$ & Arabidopsis & CC & & & & & \\
\hline & & $\begin{array}{l}\text { regulation of transcription, } \\
\text { DNA-dependent; zinc ion }\end{array}$ & $\begin{array}{l}\text { factor gata } \\
\text { (gata binding factor) }\end{array}$ & & factor 16 & & thaliana & $\mathrm{RC}$ & & & -1.5 & & \\
\hline & & $\begin{array}{l}\text { binding; sequence-specific } \\
\text { DNA binding }\end{array}$ & & & & & & IC & & & & & \\
\hline Glyma19g41800 & Kinesin motor & ATPase activity microtubule & Kinesin heavy chain & Kinesin & Kinesin heavy chain, & $0 \mathrm{E}+00$ & Ricinus & CC & -5.1 & -5.6 & -6.7 & -2.9 & -3.3 \\
\hline & & $\begin{array}{l}\text { Dinding microtubule } \\
\text { motor activity }\end{array}$ & & & & & & $\mathrm{RC}$ & & & & 2.0 & \\
\hline
\end{tabular}




\section{Table 5 Genes with significant expression differences in the $\mathbf{R}$ group vs. $\mathbf{S}$ group in qRT-PCR. $\mathbf{P}<0.05$, Fold difference $>1.5$ (Continued)}

\begin{tabular}{|c|c|c|c|c|c|c|c|c|c|c|c|c|}
\hline & & & & & & & & IC & $-5.4-6.2$ & -7.1 & -6.2 & -2.7 \\
\hline \multirow[t]{3}{*}{ Glyma19g41870 } & \multirow{3}{*}{$\begin{array}{l}\text { Protein } \\
\text { phosphatase } 2 C\end{array}$} & \multirow{3}{*}{$\begin{array}{l}\text { Protein serine/threonine } \\
\text { phosphatase activity }\end{array}$} & \multirow{3}{*}{ Protein phosphatase $2 \mathrm{C}$} & \multirow{3}{*}{$\begin{array}{l}\text { Serine/threonine } \\
\text { protein } \\
\text { phosphatase }\end{array}$} & \multirow{3}{*}{$\begin{array}{l}\text { Protein phosphatase } \\
2 c \text {, putative }\end{array}$} & \multirow[t]{3}{*}{$\mathrm{OE}+00$} & \multirow{3}{*}{$\begin{array}{l}\text { Ricinus } \\
\text { communis }\end{array}$} & CC & & & & \\
\hline & & & & & & & & $\mathrm{RC}$ & & 1.6 & & \\
\hline & & & & & & & & IC & & & & \\
\hline \multirow[t]{3}{*}{ Glyma19g41900 } & \multirow[t]{3}{*}{ F-box domain } & \multirow[t]{3}{*}{-} & \multirow[t]{3}{*}{ - } & \multirow[t]{3}{*}{-} & \multirow{3}{*}{$\begin{array}{l}\text { Phloem-specific lectin } \\
\text { PP2-like protein }\end{array}$} & \multirow{3}{*}{$2 \mathrm{E}-82$} & \multirow{3}{*}{$\begin{array}{l}\text { Arabidopsis } \\
\text { thaliana }\end{array}$} & $\mathrm{CC}$ & & & & \\
\hline & & & & & & & & $\mathrm{RC}$ & & 1.9 & & \\
\hline & & & & & & & & IC & & & & \\
\hline \multirow[t]{3}{*}{ Glyma19g41930 } & \multirow{3}{*}{$\begin{array}{l}\text { Leucine Rich } \\
\text { Repeat }\end{array}$} & \multirow[t]{3}{*}{ Protein binding } & \multirow{3}{*}{$\begin{array}{l}\text { F-box/leucine rich } \\
\text { repeat protein }\end{array}$} & \multirow{3}{*}{$\begin{array}{l}\text { Leucine rich repeat } \\
\text { proteins, some } \\
\text { proteins contain } \\
\text { F-box }\end{array}$} & \multirow{3}{*}{$\begin{array}{l}\text { Ubiquitin-protein } \\
\text { ligase, putative }\end{array}$} & \multirow[t]{3}{*}{$O E+00$} & \multirow{3}{*}{$\begin{array}{l}\text { Ricinus } \\
\text { communis }\end{array}$} & CC & & & & \\
\hline & & & & & & & & $\mathrm{RC}$ & & & 2.1 & \\
\hline & & & & & & & & IC & & & & \\
\hline \multirow[t]{3}{*}{ Glyma19g42050 } & \multirow{3}{*}{$\begin{array}{l}\text { Calcineurin-like } \\
\text { phosphoesterase }\end{array}$} & \multirow{3}{*}{$\begin{array}{l}\text { Protein serine/threonine } \\
\text { phosphatase activity }\end{array}$} & \multirow{3}{*}{$\begin{array}{l}\text { Serine/threonine } \\
\text { protein } \\
\text { phosphatase }\end{array}$} & \multirow{3}{*}{$\begin{array}{l}\text { Serine/threonine } \\
\text { specific protein } \\
\text { phosphatase PP1, } \\
\text { catalytic subunit }\end{array}$} & \multirow{3}{*}{$\begin{array}{l}\text { Serine/threonine- } \\
\text { protein } \\
\text { phosphatase PP1 } \\
\text { isozyme } 8\end{array}$} & \multirow[t]{3}{*}{$\mathrm{OE}+00$} & \multirow{3}{*}{$\begin{array}{l}\text { Arabidopsis } \\
\text { thaliana }\end{array}$} & CC & & & & \\
\hline & & & & & & & & $\mathrm{RC}$ & & 1.8 & & \\
\hline & & & & & & & & IC & & & & \\
\hline Glyma19g42120 & - & - & - & Uncharacterized & heparan-alpha- & $0+00$ & Arabidopsis & CC & & & & \\
\hline & & & & conserved proteln & $\begin{array}{l}\text { glucosaminide } \\
\text { N-acetyltransferase }\end{array}$ & & thallana & $\mathrm{RC}$ & & & 2.0 & \\
\hline & & & & & & & & IC & & & & \\
\hline Glyma19g42200 & Rapid ALkalinization & Signal transducer activity & - & - & Rapid ALkalinization & $9 e-47$ & Medicago & CC & & & & \\
\hline & Factor (RALF) & & & & Factor & & truncatula & $\mathrm{RC}$ & & 1.6 & & \\
\hline & & & & & & & & IC & & & & \\
\hline Glyma19g42340 & Protein tyrosine & Protein-tyrosine kinase & Mapkk-related & MEKK and related & Mitogen activated & $\mathrm{OE}+00$ & Ricinus & CC & & & & \\
\hline & & $\begin{array}{l}\text { activity; protein amino } \\
\text { acid phosphorylation; }\end{array}$ & $\begin{array}{l}\text { serine/threonine } \\
\text { protein kinases }\end{array}$ & $\begin{array}{l}\text { serine/threonine } \\
\text { protein kinases }\end{array}$ & $\begin{array}{l}\text { protein kinase } \\
\text { kinase kinase 3, }\end{array}$ & & communis & $\mathrm{RC}$ & & & 2.8 & \\
\hline & & ATP binding & & & $\begin{array}{l}\text { mapkkk3, mekk3, } \\
\text { putative }\end{array}$ & & & IC & & & 2.1 & 2.0 \\
\hline
\end{tabular}

R group: lines with the Conrad haplotype (Conrad, the RILS 2022, and 1960); S group: lines with the
negative value indicates the fold of greater expression ratio in the group with the Sloan haplotype.

a PFAM description provided by the Soybean Genome Project, DoE Joint Genome Institute (http://www.phytozome.net/soybean.php, updated on July 2011);

${ }^{\mathrm{b}}$ Gene Ontology Descriptions obtained from the (http://soybase.org, updated on July 2011).

c PANTHER description provided by the Soybean Genome Project, DoE Joint Genome Institute (http://www.phytozome.net/soybean.php, updated on July 2011);

d KOG Description assigned by the Soybean Genome Project, DoE Joint Genome Institute (http://www.phytozome.net/soybean.php, updated on July 2011);

e CC: Constitutive contrast-significant fold difference in transcript abundance between the group with Conrad haplotype and the group with Sloan haplotype in mock-inoculated samples at specified time points

CC: Constitutive contrast-significant fold difference in transcript abundance between the group with Conrad haplotype and the group with Sloan haplotype in mock-inoculated samples at specified time points
(hai);

${ }^{\dagger}$ RC: Response contrast-significant fold differences in infection response ratios (inoculated / mock-inoculated) in the group with Conrad haplotype compared to the group with Sloan haplotype at specified time
points (hai); points (hai);

${ }^{9}$ IC: Infection contrast-significant fold difference in transcript abundance between the group with Conrad haplotype and the group with Sloan haplotype in infected samples at specified time points (hai);

${ }^{\mathrm{h}}$ Samples were collected from the inoculation site at $72 \mathrm{HAl}$

' Samples were collected from the front of lesion margin at $72 \mathrm{HAI}$. 


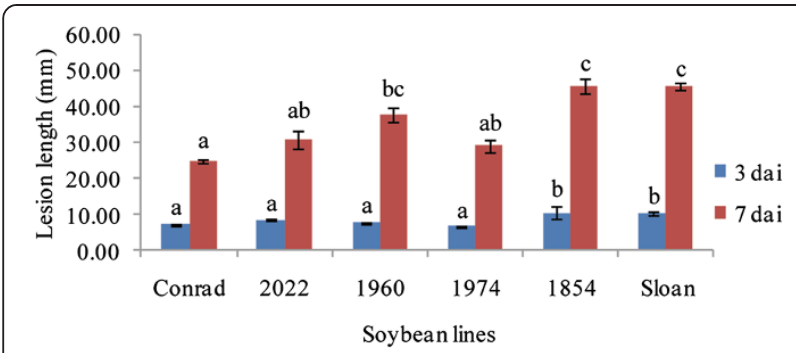

Figure 4 Lesion lengths of the six lines for qRT-PCR after inoculation with Phytophthora sojae. The data at 3 day after inoculation (dai) were collected from the GRT-PCR assay while the data at 7 dai were collected from the mapping study of the Conrad $\times$ Sloan $\mathrm{F}_{6: 8}$ population. For each time point, bars with different letters indicate the significantly different lesion lengths $(P<0.05)$.

eight genes (Table 3) and potentially contribute to the differences in partial resistance by modified protein structure(s).

Twenty-seven of 29 selected SNPs (one per gene) were verified by a modified polymerase chain reaction (PCR) amplification of multiple specific alleles (PAMSA) [37]. Locus-specific primers could not be found for the SNP in
Glyma19g42510, of which a highly homologous copy was present on Chr. 3. Sanger sequencing of the PAMSA amplicons of the second gene not confirmed by PAMSA, Glyma19g41420, identified a 22 bp deletion instead of the predicted SNPs at 918-939 bp upstream (Additional file 4). This gene is predicted to encode a serine/threonine protein kinase and microarray analysis indicated a similar level of down-regulation in both $\mathrm{R}$ and $\mathrm{S}$ at 2 dai [10]. Thus, the deletion in the upstream region most likely did not cause the infection response observed in both $R$ and $\mathrm{S}$ in the microarray analysis.

\section{Candidate genes underlying the QTL and their expression patterns}

Microarray data was available for 21 of the 53 genes from QTL 19-1, and 83 of the 175 genes under QTL $19-2[10,21]$. Of these, 15 genes from QTL $19-1$ and 64 from QTL 19-2 responded significantly to infection in $\mathrm{R}$ or $\mathrm{S}$ genotypes. The highest percentages of genes (78.9-93.8\%) with infection response were observed in the 'Signal transduction', 'Metabolism,' 'Unknown', and 'Transcription factor' categories (Figure 1). To further differentiate the potential candidate defense genes
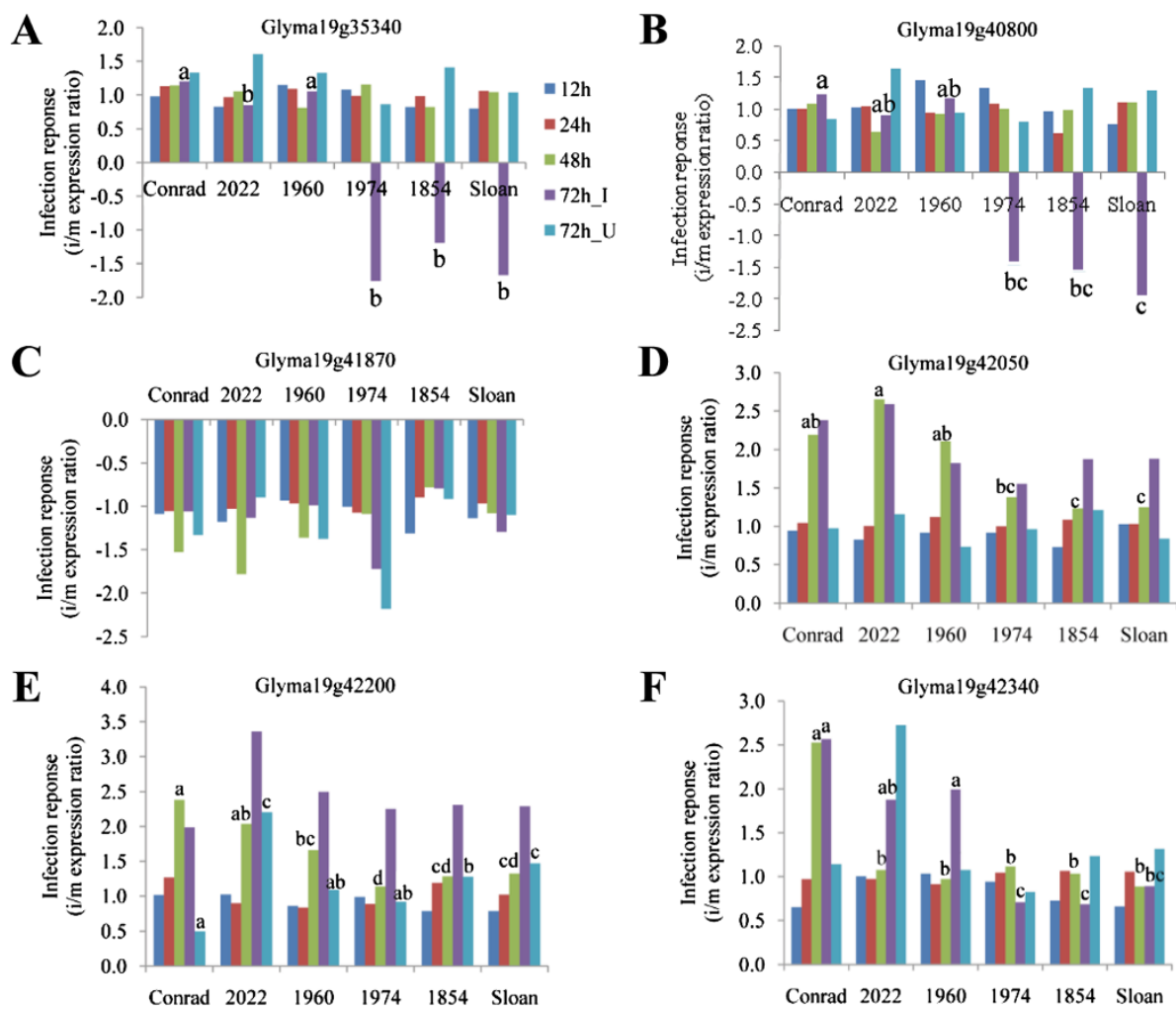

Figure 5 Signaling genes from QTL 19-1 and 19-2 with significant infection response in qRT-PCR assays. A. Glyma19g35340 (Alcohol dehydrogenase, class III); B. Glyma19g40800 (transducin/WD40 domain-containing protein); C. Glyma19g41870 (Protein phosphatase 2C); D. Glyma19g42050 (Calcineucin-like phosphatase); E. Glyma19g42200 (Rapid alkalinization factor RALF); F. Glyma19g42340 (MAP3K-ANP1-like). Bars labeled with different letters indicate the significantly different infection response between samples at a specific time point $(P<0.05)$. Letters only appear above the bars of time points for which there were significant differences between Conrad and Sloan. 
within the QTL regions, one gene from QTL 19-1 and 18 genes from QTL 19-2 were examined for their expression patterns in response to $P$. sojae infection at $12,24,48$, and 72 hai in R, S, and four selected RILs using qRT-PCR (Tables 1, 2, 3, 4, and 5, Additional files 1, and 2). The genes were selected based on their annotated functions, sequence variation and differential expression patterns from microarray data between $\mathrm{R}$ and S. Eight of the genes had microarray data with significant infection response in $R$, of which six genes had SNPs between R and S. A total of 15 genes in qRT-PCR assay had SNPs between R and S, with eight genes harboring unique sequence in $\mathrm{R}$ compared to both $S$ and Williams 82. The presence of $R$ and $S$ alleles of these genes in the four RILs was verified by PAMSA (Table 1).

During the qRT-PCR experiments, lesion symptoms were not visible until 72 hai, which was the same timing as symptom development reported in the microarray assays $[10,21]$. Samples for analysis were collected at the inoculation site for the first three time points. At 72 hai, significantly longer lesions were observed in $\mathrm{S}$ and RIL 1854 in comparison to the remaining four lines $(P<0.05$, Figure 4); tissue samples were collected both above the lesion margin, similar to the microarray assays $[10,21,22]$, and at the inoculation site. Most changes of transcript abundance were observed at 48 and 72 hai, which was similar to the previous findings that most of the transcript abundance changes in the expression of partial resistance to $P$. sojae in soybean occurred 48 hai or later $[10,18,22]$. Similar expression patterns were obtained with qRT-PCR compared to microarray data for six of the eight genes at all time points. However, Glyma19g42240 and Glyma19g42460 (Histone-like transcription factors) had suppressed transcript levels at 48 hai in microarray assays [10], but not in the qRT-PCR assays.

Overall, sixteen of the genes analyzed with qRT-PCR had significant differences in transcript levels between $R$ and $\mathrm{S}$ in either mock-inoculated samples, infected samples, or infection response $(P<0.05$, fold difference $>1.5$, Table 4). These three types of expression contrasts were also analyzed between the three lines harboring the $R$ haplotype ( $\mathrm{R}$ group, Table 1 ) and the three lines with the $S$ haplotype (S group, Table 1) with significant differences observed for 15 genes $(P<0.05$, fold difference $>$ 1.5 , Table 5). Significantly different infection responses in 11 genes were observed between $\mathrm{R}$ and $\mathrm{S}$, as well as between the $\mathrm{R}$ and $\mathrm{S}$ group (Tables 4 and 5). Eight of the 11 genes had SNPs in upstream, UTR, exon, intron, or downstream region. The annotated functions and differential expression patterns of these 11 genes suggested their potential association with the higher level of partial resistance in $\mathrm{R}$ compared to $\mathrm{S}$.

\section{Signaling genes}

Five genes with annotated functions in signal transduction were found to be associated with the high level of partial resistance in R. Calcineurin-like phosphatase (Glyma19g42050) is a $\mathrm{Ca}^{2+}$ - and calmodulin-dependent serine/threonine phosphatase. It was up-regulated at 48 hai in the $\mathrm{R}$ group, which was $24 \mathrm{~h}$ earlier than the $\mathrm{S}$ group (Figure 5). This gene is involved in calcium-signaling, which is an important component of plant-pathogen interactions [38]. Repression of calcineurin-like proteins resulted in hypersensitivity to abscisic acid ( $\mathrm{ABA}$ ), indicating their roles as negative regulators of an ABA signaling pathway $[39,40]$. ABA was also reported to be a negative regulator of $R$-gene mediated resistance against $P$. sojae in soybean through suppression of salicylic acid (SA)-mediated defense pathways [41,42]. The results from this study indicated calcineurin-like phosphatase in the defense pathways could contribute to the high level of partial resistance in $\mathrm{R}$ genotype. Its potential interaction with ABAsignaling needs to be further explored in future studies in the soybean partial resistance to $P$. sojae.

MAP3K is part of the MAP kinase cascade, which is known to be one of the early signaling events in PAMPtriggered immunity (PTI). The MAP3K-ANP1 gene in Arabidopsis was reported to suppress early auxin response but activate MPK3 and MPK6, which are the positive regulators of plant defense in PTI $[43,44]$. In this study, a MAP3K-ANP1-like gene Glyma19g42340 with 11 SNPs in $\mathrm{S}$ compared to both $\mathrm{R}$ and Williams 82, with seven in the upstream, three in the introns, and one synonymous SNP was identified. The MAP3KANP1-like gene was up-regulated during infection in the $R$ genotype at 48 and 72 hai. This gene also exhibited significantly higher transcript abundances in the R group than the $\mathrm{S}$ group at the inoculation sites 72 hai (Figure 5, Table 5). These transcriptional results make this a candidate gene that may be involved in regulating soybean defense to $P$. sojae.

Class III alcohol dehydrogenase (ADH), is also known as the glutathione-dependent formaldehyde dehydrogenase (FALDH) or S-nitrosoglutathione reductase (GSNOR). It functions in nitric oxide (NO) signaling, which is an important signaling pathway in regulating defense gene expression, defense hormone interplay, and oxidative stress response during plant-pathogen interactions [45-48]. In Arabidopsis the orthologous gene, $A D H 2$, has been demonstrated to positively regulate basal resistance to Pseudomonas syringae and Hyaloperonospora parasitica through activating SA-mediated defense pathway [46]. However, another study reported that down-regulation of $\mathrm{ADH} 2$ increased the basal resistance in Arabidopsis to $H$. parasitica [48]. In this study, an $\mathrm{ADH} 2$ ortholog in soybean (Glyma19g35340) had 19 SNPs in S compared 

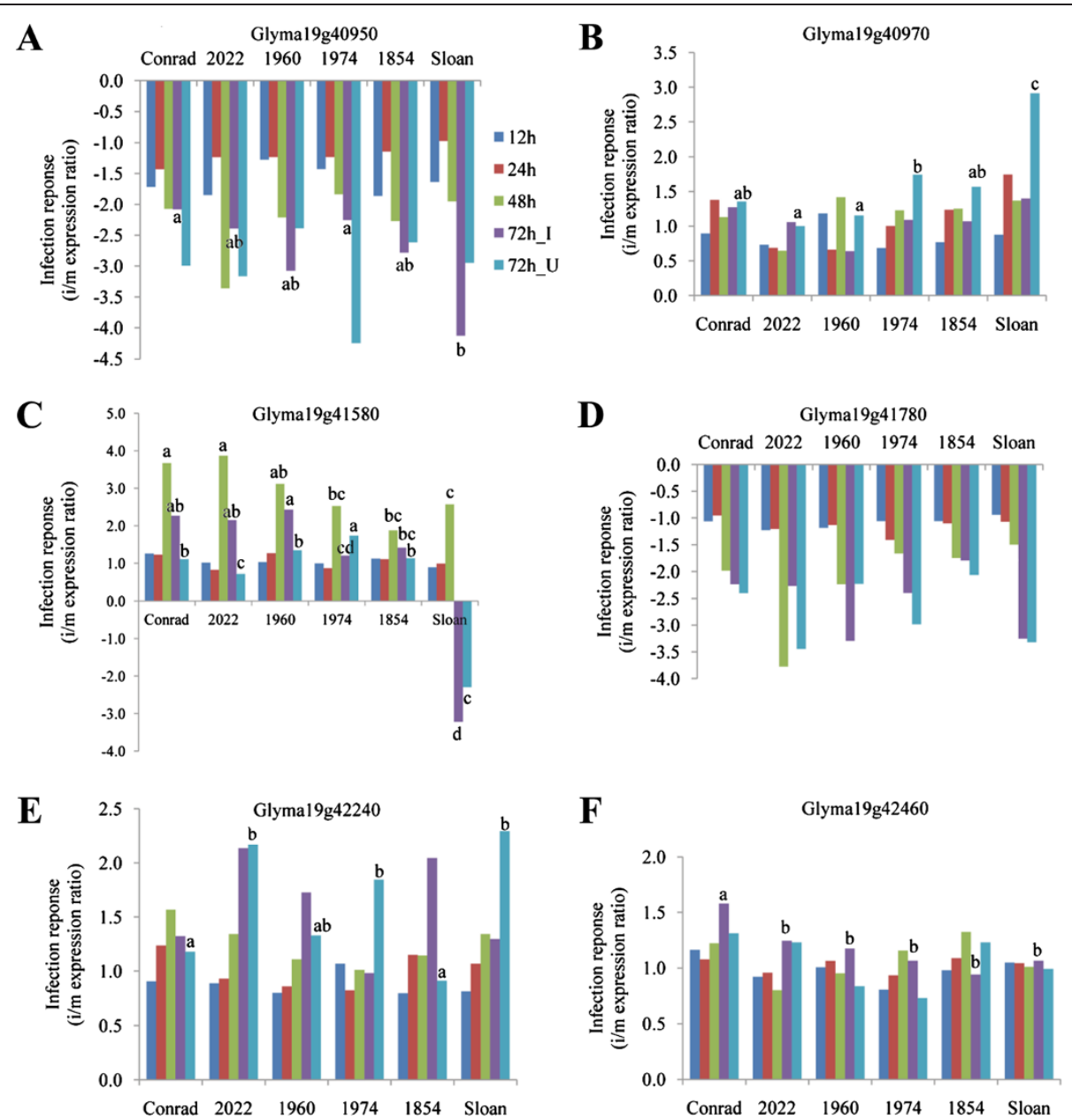

Figure 6 Transcription factors from QTL 19-2 with significant infection response in qRT-PCR assays. A. Glyma19g40950 (WRKY transcription factor); B. Glyma19g40970 (Auxin-responsive transcription factor); C. Glyma19g41580 (putative bHLH transcription factor); D. Glyma19g41780 (GATA Zinc-finger transcription factor); E. Glyma19g42240 (Histone-like transcription factor); F. Glyma19g42460 (Histone-like transcription factor). Bars labeled with different letters indicate the significantly different infection response between samples at a specific time point $(P<0.05)$. Letters only appear above the bars of time points for which there were significant differences between Conrad and Sloan.

to both $\mathrm{R}$ and Williams 82, in the upstream, exon (one of the two SNPs was non-synonymous), intron, 3' UTR and downstream regions. It was down-regulated at the inoculation sites 72 hai in the S group only (Figure 5). The suppression of this gene may potentially contribute to the susceptibility of soybean to $P$. sojae.

Rapid alkalinization factor (RALF) was first identified in a search for bioactive defense peptides in tobacco, and it was reported to promote extracellular alkalinity and activate MAP kinases [49]. Significantly higher levels of RALF activation were observed in the resistant variety of chickpea in comparison to the susceptible one at 48 hai with Fusarium oxysporum [50]. Interestingly, in a study with poplar, methyl jasmonate (MeJA) treatment was found to strongly suppress RALF expression [51], which may indicate that the defense pathways associated with activation of
RALF were different than the jasmonic acid (JA)mediated pathway. In this study, a RALF-encoding gene (Glyma19g42200) had unique sequence in $R$ compared to both $\mathrm{S}$ and Willams82 (Table 2). It was up-regulated in the $\mathrm{R}$ group at 48 hai, which was $24 \mathrm{~h}$ earlier than the $\mathrm{S}$ group (Figure 5). These results suggest its potential association with partial resistance in $R$.

A transducin/WD40 domain-containing protein (Glyma19g40800) had unique sequence in R compared to both $\mathrm{S}$ and Williams82 (Table 2). It was down-regulated in the $S$ group only at the inoculation site 72 hai (Figure 5). Members of this class of genes in other plant species have been reported to be up-regulated in the resistant response to pathogen infection, such as in potato against $P$. infestans [52] and in Arabidopsis against Colletotrichum higginsianum [53]. The suppression of this 

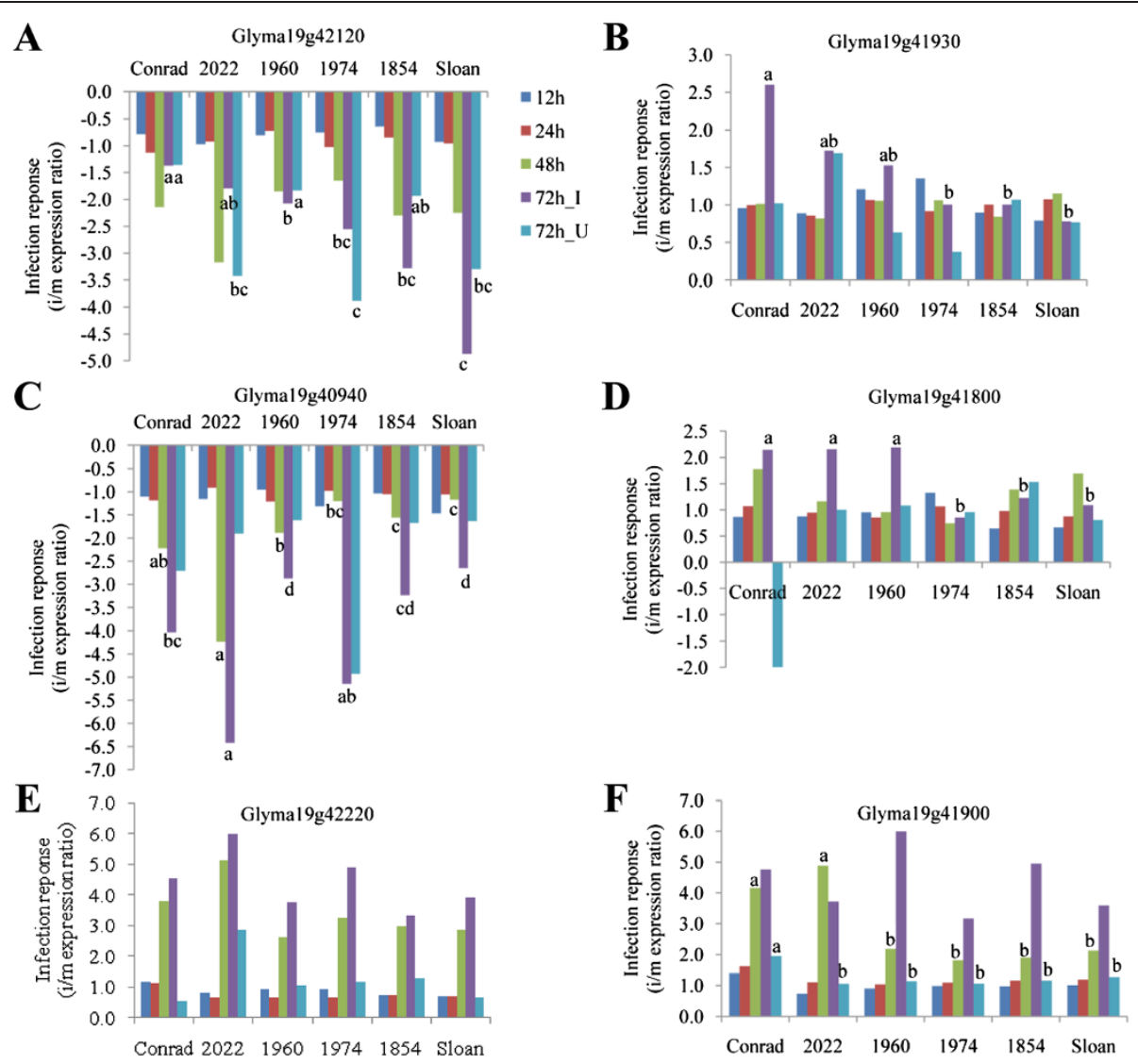

Figure 7 Genes from different functional categories in QTL 19-2 with significant infection response in qRT-PCR assays. A. Metabolism: Glyma19g42120 (heparan-alpha-glucosaminide N-acetyltransferase); B. Protein modification: Glyma19g41930 (putative ubiquitin-protein ligase); C. Cell wall: Glyma19g40940 (Glycosyl hydrolases family 28); D. Cytoskeleton: Glyma19g41800 (Kinesin motor); E. oxidation: Glyma19g42220 (Calcium-binding oxidoreductase); and F. Other: Glyma19g41900 (putative phloem-specific lectin PP2). Bars labeled with different letters indicate the significantly different infection response between samples at a specific time point $(P<0.05)$. Letters only appear above the bars of time points for which there were significant differences between Conrad and Sloan.

gene in soybean may potentially contribute to the susceptibility to $P$. sojae.

\section{Genes involved in hormone-mediated pathways}

Auxin signaling and transport has been found in several other pathosystems to promote plant susceptibility to bacterial and fungal pathogens [54-56]. In Arabidopsis, PTI suppressed the binding of Auxin-responsive TFs to the promoters of downstream genes, hence downregulating the auxin-response pathway [57]. In soybean$P$. sojae interactions, transcript abundance of a PIN1-like auxin transport protein and an auxin-induced protein were both found to be up-regulated in $\mathrm{S}$ but were suppressed in $\mathrm{R}$ at 3 and 5 dai [10]. In this study, an auxinresponsive TF (Glyma19g40970) was up-regulated only in the $S$ group at the infection front 72 hai (Figure 6). At the same time, the infected samples of $S$ group also had significantly higher transcript abundance than the $R$ group (Table 5). These results suggest the potential role of auxin may be in the susceptible response, and one of the partial resistance mechanisms in $\mathrm{R}$ may be the suppression of $P$. sojae-induced auxin-signaling.

A bHLH TF, MYC2, was reported to positively regulate JA response to wounding and insect attack, but negatively regulate the JA response to pathogen infection [58]. This gene has been proposed to be a key regulator in the crosstalk among SA-, JA-, ET-, and ABAmediated signaling pathways $[59,60]$. A putative bHLH TF (Glyma19g41580) in this study had one SNP at the 251 bp upstream in R compared to both $\mathrm{S}$ and Williams 82 , and the other synonymous SNP in an exon. Significantly higher level of up-regulation was observed with this gene in the $\mathrm{R}$ group at the inoculation site 48 and 72 hai (Figure 6, Table 5), which again indicated the potential involvement of these hormone-mediated pathways in soybean partial resistance to $P$. sojae.

As observed in previous studies [4], the disease symptoms in this study were first observed in soybean roots at 72 hai with $P$. sojae, which indicated that biotrophic stage of infection occurred at inoculation site during the first 
48 hai, while necrotrophic stage can be seen at 72 hai. The genes encoding bHLH and auxin-responsive TFs, together with the calcineurin-like phosphatase encoding gene, MAP3K-ANP1-like gene, and RALF signaling gene discussed earlier, were all induced in $\mathrm{R}$ group during biotrophic infection. Based on the functional studies of these genes in different pathosystems combined with the analyses in this study, it indicates the potential involvement of SA-mediated pathway, accompanied by suppression of auxin-, and/or ABA-mediated pathways contributing to the expression of partial resistance to $P$. sojae in soybean. Interestingly, auxin-, ABA-, or JA-signaling have each been reported to work antagonistically with SA against (hemi)biotrophic pathogens, and elevated SA levels will suppress these three hormone-mediated pathways $[59,60]$. The cross-talk among these hormone-mediated pathways and their contribution to partial resistance in soybean against $P$. sojae should be a focus in future studies.

\section{Genes involved in modification of plant cell structures}

Modification of plant cell structures is an important aspect of plant defense response and three genes, each involved in modification of cell wall, cytoskeleton, and phloem structure, potentially contributed to the expression of partial resistance to $P$. sojae. Glycosyl hydrolase 28 (GH28) hydrolyses pectin is one of the major components of plant cell walls [61-63]. Many bacterial and fungal pathogens secret this enzyme to help them penetrate plant cells [64-66]. In this study, a GH28encoding gene (Glyma19g40940) had a unique sequence in $\mathrm{R}$ as compared to both $\mathrm{S}$ and Williams82 (Table 2). Transcription for this gene was down-regulated at 48 hai in the $\mathrm{R}$ group, which was $24 \mathrm{~h}$ earlier compared to the $\mathrm{S}$ group (Figure 7) and may indicate the suppression of cell wall degradation as one of the many components in the expression of partial resistance in soybean against $P$. sojae.

Kinesin motor is one of the cytoskeletal motors, which may participate in defense responses when a plant is challenged by environmental stresses or pathogen attacks $[67,68]$. A kinesin motor (Glyma19g41800) in this study had a predicted premature stop codon in $R$, and the resulting peptide is predicted to be missing 650 amino acids from the C-terminus compared to both $\mathrm{S}$ and Williams 82 (Table 3, Additional file 4). It had significantly lower transcript abundance in both mock-inoculated and infected samples of the $\mathrm{R}$ group than the $\mathrm{S}$ group (Tables 4 and 5), possibly due to the predicted truncated protein in R; however, this needs to be validated. In addition, this gene was up-regulated at the inoculation site 72 hai only in the $R$ group (Figure 7 ), which may indicate the potential involvement of the $\mathrm{R}$ allele in soybean partial resistance against $P$. sojae.
Plant lectins belong to a large gene family with diverse functions, one of which is the anti-microbial function in plant defense [69-71]. Soybean cultivars with $R$-gene mediated resistance towards $P$. sojae were found to have two-fold more lectins in seeds than susceptible cultivars [72]. Phloem-specific lectins are also known to be related with defined stages of phloem differentiation [73], and their interaction with mesophyll plasmodesmata are known to increase the size exclusion limit of movement between cells [74]. In this study, a putative phloem-specific lectin PP2 gene (Glyma19g41900) had unique sequence in $\mathrm{R}$ compared to both $\mathrm{S}$ and Williams82 (Table 2 and 3). It was up-regulated at the inoculation site at 48 and 72 hai across all the resistant and susceptible lines, however, significantly higher fold changes were observed in the R group at 48 hai (Figure 7 , Table 5 ). Thus this gene may also potentially contribute to the higher level of partial resistance of soybean to P. sojae.

\section{Genes involved in ubiquitination}

Ubiquitination, which functions in protein modification and degradation, has been found to be an important regulator of plant defense response, such as the oxidative burst, hormone signaling, gene induction, and programmed cell death [75]. Ubiquitin ligases are the key enzymes to select target proteins for ubiquitination. These ligases have been reported to regulate SA-, JA/ET-mediated pathways and they could have either positive or negative effect on plant defense $[75,76]$. In this study, a putative ubiquitin-protein ligase (Glyma19g41930) was activated at the inoculation site 72 hai in the $R$ group only (Figure 7 ), which may indicate this gene as a positive regulator of soybean partial resistance against $P$. sojae.

From the 11 genes discussed earlier, three genes, an auxin-responsive TF, a transducin/WD40 domaincontaining protein, and a class III alcohol dehydrogenase, all had significant infection response in $\mathrm{S}$ group only. Their annotated functions suggested that these responses may potentially contribute to the soybean susceptibility to $P$. sojae. The response of auxin-responsive TF was observed 72 hai at infection front, where biotrophic infection occurred; whereas the other two genes were down-regulated 72 hai at inoculation site, where the necrotrophic phase is in progress. Distinct effector proteins have been found to be secreted by another oomycete pathogen, $P$. infestans, during biotrophic and necrotrophic stages of infection [77]. Thus, secreted effectors from $P$. sojae may also mediate the different stages of infection, potentially targeting these three genes as well as others to suppress the defense response. Further studies are needed to assess if the sequence variation of these genes contributes to the pathogen 
effector-target recognition process, which in turn contribute to the higher level of partial resistance.

\section{Conclusions}

It is usually difficult to demonstrate the effect of each individual gene underlying a QTL on partial resistance due to the large number of genes with minor and additive effects on the phenotypes [78]. In this study, we utilized sequence and expression analysis to efficiently identify candidate genes underlying the soybean QTL conferring resistance to $P$. sojae. Two QTL were dissected by sequence and gene expression analysis between the resistant and susceptible genotypes. A list of candidate genes was identified, including those potentially involved in signal transduction, hormone-mediated defense pathways, plant cell structural modification, and ubiquitination. Also, several genes from this list have been reported for their roles in PTI in heterologous systems, which may indicate that basal resistance may be another component of partial resistance. These findings supported our hypothesis that defense to $P$. sojae may be a coordinated, multifaceted response to infection. Eleven of the 15 genes with SNPs had significantly different changes in transcript abundance between the $\mathrm{R}$ and $\mathrm{S}$ genotypes in response to $P$. sojae infection in the qRT-PCR assay, which also supports our hypothesis that SNP analysis could expedite the identification of candidate genes involved in partial resistance. In addition to transcriptional regulation examined in this study, other regulatory mechanisms, including post-transcriptional and translational regulation, could contribute to the differential partial resistance levels between $\mathrm{R}$ and $\mathrm{S}$ and represent interesting targets for future studies. Whole-genome sequencing of these two cultivars may aid in the discovery of Conradspecific genes, which may contribute to partial resistance. Overall, this study provides an initial list of candidate genes for further study and additional SNP markers for fine mapping and marker-assisted breeding of soybean partial resistance to $P$. sojae.

\section{Methods}

\section{Plant resources}

An $\mathrm{F}_{6: 8}$ recombinant inbred line (RIL) population was developed from a cross of soybean cultivar R (Conrad) by $\mathrm{S}$ (Sloan). This population was advanced by single seed descent from the $\mathrm{F}_{4: 6}$ population that was used in the studies of $[10,11]$.

\section{Inoculum and phenotypic assay}

The 246 RILs of the $F_{6: 8}$ Conrad $\times$ Sloan population were evaluated for the expression of resistance by measuring lesion length following inoculation with $P$. sojae isolate 1.S.1.1 (vir 1a, 1b, $1 \mathrm{k}, 2$, 3a, 3b, 3c, 4, $5,6,7,8)$ using the tray test assay, of which the procedure was described in detail previously $[6,10,79]$. Roots of 7-day-old soybean seedlings were inoculated $20 \mathrm{~mm}$ below the crown. Seven dai, the lesion on each seedling was measured from the point of inoculation up to the top of lesion margin. The experimental design was an augmented randomized complete block (RCB), with at least 82 RILs evaluated within each block. The $\mathrm{R}$ and $\mathrm{S}$ parents were included in each block and there were three blocks within each experiment. Each RIL was evaluated three times in three separate experiments. For phenotypic data analysis, BLUP values of each RIL was obtained using a mixed model analysis with the mean lesion length of the 10 plants in each tray, as described in [6,9-11]. Heritability, on a family mean basis, was calculated as described in [10].

\section{QTL mapping}

DNA from each RIL was extracted using the same method as [10]. For this population, 147 RILs were randomly selected and genotyped using the Illumina BeadXpress ${ }^{\circledR}$ Assay (Illumina Inc., San Diego, CA) according to manufacturer's protocol. DNA samples were first quantified with Picogreen ${ }^{\circledR}$ dsDNA quantification kit (Invitrogen Inc., Carlsbad, CA) and $250 \mathrm{ng}$ each (50 ng/ul) was used for BeadXpress genotyping, including several activation and ligation steps followed by PCR, hybridization to SNP-specific beads, washing, and plate scanning at the Molecular Cellular Imaging Center (MCIC, OARDC, Wooster, OH). The genotype data was analyzed using the Genome Studio Software ${ }^{\circledR}$ (Illumina Inc., San Diego, CA). A total of 151 SNP markers $[33,35,80]$ were used to build the genetic map using JoinMap ${ }^{\circledR} 4.0$ with the Kosambi function [81]. A preliminary analysis with interval mapping to identify potential QTL on 147 RILs in response to $P$. sojae inoculation with MAPQTL ${ }^{\circledR} 5.0$ [82] and single marker association with one-way ANOVA (Proc GLM, SAS 9.1.3, SAS Institute Inc. Cary, NC) was done.

A total of 57 SSR and 32 SNP markers which targeted the potential QTL regions were genotyped on the 246 RILs. For SNP genotyping, a modified PCR Amplification of Multiple Specific Alleles (PAMSA) technique was used [37]. The procedures of SNP and SSR genotyping were as described in [11]. The genetic map for these potential QTL regions was re-constructed using JoinMap ${ }^{\circledR}$ 4.0 with the Kosambi function [81]. Interval mapping (IM) and composite interval mapping (CIM) of QTL were performed using MAPQTL ${ }^{\circledR} 5.0$ [82]. The walking speed for QTL analyses was 1.0 centimorgan (cM). Permutation tests with 1000 iterations were performed on each linkage group and on the whole genome to estimate significant LOD scores [83]. 
Functional categorization of genes underlying the QTL Genes underlying the QTL were categorized into 14 groups based on their functional annotations from NCBI BLASTP search and four other databases (GO Function, PFAM, PANTHER, and KOG) [23]. Grouping criteria, modified from [84], included: 1) Signal transduction, which involves calcium signaling genes, G proteins, kinases and phosphatases, and other signal transducers; 2) Metabolism, including genes in both primary and secondary metabolic pathways; 3) Unknown, including genes with no annotations or no characterized functions from all mentioned databases; 4) Protein modification, including genes involved in proteins synthesis, degradation and other structural modification processes; 5) Transcription factor; 6) Transporter; 7) Cell wall, which includes genes in synthesis and modification of different cell wall components; 8) RNA regulation, which involves RNA-binding genes; 9) Energy, which includes genes associated with ATP and electron transfer; 10) Stress response; 11) Cytoskeleton, which involves actin, kinesin, and microtubule-related genes; 12) Oxidation, which includes genes encoding enzymes involved in oxidation; and 13) Pathogenesis-related (PR) protein; and 14) Others, which includes genes not in the previously mentioned categories.

\section{Long-range PCR (LR-PCR)}

Gene sequences were extracted from the soybean reference genome which was generated from the cultivar Williams82 [23]. A total of 217 pairs of gene-specific primers were designed using BatchPrimer3 [85] for 186 genes underlying the QTL 19-1 and 19-2. For each gene, a $1.2 \mathrm{~kb}$ upstream region and a 400 bp downstream region were included for primer design. LR-PCR was performed with a $30 \mu \mathrm{l}$ PCR reaction which contained $30 \mathrm{ng}$ of genomic DNA template, $1 \times$ Phusion HF buffer (New England Biolabs Inc., Ipswich, MA.), $200 \mu \mathrm{M}$ dNTPs, $0.4 \mu \mathrm{M}$ forward and reverse primers, and $0.6 \mathrm{U}$ of Phusion ${ }^{\circledR}$ High-Fidelity DNA Polymerase (New England Biolabs Inc., Ipswich, MA.). PCR reactions were performed using the following conditions: $98^{\circ}$ $\mathrm{C}$ for $2 \mathrm{~min}, 35$ cycles of $98^{\circ} \mathrm{C}$ for $10 \mathrm{sec}$, (lower Tm calculated by the nearest neighbor method +3$)^{\circ} \mathrm{C}$ for $30 \mathrm{sec}$, and $72^{\circ} \mathrm{C}$ for $6 \mathrm{~min}$, followed by a final extension at $72^{\circ} \mathrm{C}$ for $10 \mathrm{~min}$. PCR products were purified by the E-Gel ${ }^{\circledR}$ Clonewell $0.8 \%$ SYBR Safe ${ }^{\mathrm{TM}}$ agarose and $2 \%$ SizeSelect $^{\mathrm{TM}}$ agarose (Invitrogen Inc., Carlsbad, CA), and the Zymoclean ${ }^{\mathrm{TM}}$ Gel DNA Recovery kit (ZymoResearch Inc., Irvine, CA). The purified PCR products were quantified in $2 \%$ agarose gel with ethidium bromide staining. Equal amounts (30 ng) of each PCR product amplified from $\mathrm{R}$ and $\mathrm{S}$ cultivars were pooled separately and precipitated with $100 \% \mathrm{EtOH}$ to remove the fluorescent dyes which bound to DNA from the E-gels. The purified PCR product pools were quantified again in $2 \%$ agarose gel prior to library construction.

\section{Library construction for Illumina GA II sequencing}

Approximately $3 \mu \mathrm{g}$ of combined PCR products from $\mathrm{R}$ or $\mathrm{S}$ were used for library preparation. PCR products were digested with NEBNext dsDNA Fragmentase (New England Biolabs Inc., Ipswich, MA.) according to manufacturer's instructions. Reactions were carried out in a total volume of $60 \mu \mathrm{l}$ with $6 \mu \mathrm{l}$ of fragmentase and incubated in a $37 \mathrm{C}$ water-bath for 25 minutes. The reactions were cleaned using QIAQuick PCR Purification Kit (Qiagen, Valencia, CA). Fragmented DNA was used for Illumina Paired-End (PE) library preparation, using the PE library preparation kit (Illumina Inc., San Diego, CA) as instructed in the manual. To reduce the overrepresentation of the amplicon ends in sequencing [86], a 400-bp library instead of a standard 200-bp one was constructed. The fragments were end-repaired and phosphorylated using T4 DNA polymerase, Klenow DNA polymerase and T4 PNK and were 3 ' adenylated using Klenow Exo- (3' to 5 ' exo minus). Illumina PE adapters were ligated using DNA Ligase, followed by purification on a 2\% TAE-agarose gel (Certified Low-Range Ultra Agarose, Biorad). A band of $400 \pm 25$ bp was cut and purified, using QIAQuick Gel Extraction Kit (Qiagen, Valencia, CA). Enrichment of adapter ligated fragment and the addition of sequences necessary for flow cell binding was done by performing fifteen rounds of PCR, using Illumina PE 1.0 nd PE 2.0 primers. DNA fragment size distribution in the libraries was done with an Agilent Technologies 2100 Bioanalyzer using the Agilent DNA 1000 chip kit. The libraries were quantified, using quantitative PCR with PhiX sequencing control as a standard (Illumina, San Diego, CA). PE sequencing was done, using the Illumina GAII platform at MCIC (OARDC, Wooster, OH).

\section{Sequence data analyses}

Initial quality assessment of sequence reads was performed using Fastqc. Sequence reads with poor quality were filtered (adaptive_qualitytrim.pl). The pre-processed FASTQ files were aligned using the MOSAIKALIGNER set of tools (version 0.9.0891 of the MOSAIK Software Suite; (http://bioinformatics.bc.edu/marthlab/Mosaik). All reads were aligned to the $\mathrm{Chr} .19$ sequences from the soybean reference genome [23]. SNPs between the reference sequence (Williams82) and samples were identified using Partek Genomics Suite version 6.5 (Partek, St Louis, MO). False-positive SNPs which located outside the amplicons and/or had less than $20 \mathrm{X}$ coverage were removed. The alignment data from the $\mathrm{R}$ and $\mathrm{S}$ are available at NCBI Sequence Read Archive (SRA) under accession SRA056409. 


\section{SNP verification}

Twenty-nine SNPs were selected for verification by PAMSA technique [3], based on the $0.1 \mathrm{Mb}$ interval and predicted gene function. The SNP genotyping procedure was as described in [11]. For one SNP that was not verified by PAMSA, the PCR products from SNP genotyping were purified by Zymoclean ${ }^{\mathrm{TM}}$ Gel DNA Recovery kit (ZymoResearch Inc., Irvine, CA) and sent for Sanger sequencing at MCIC (OARDC, Wooster, OH).

\section{qRT-PCR assays}

The tray test protocol was also used for the qRT-PCR time course assay. P. sojae isolate 1.S.1.1 was used to inoculate R, S, and four selected RILs with different combination of R or S haplotypes at QTL (Table 1). Samples were collected at 12, 24, 48, and 72 hai. At the first three time points, the inoculation site was sampled; and at 72 hai, lesions were measured and the $0.75 \mathrm{~mm}$ from the edge of lesion margin and above was sampled for RNA extraction. For control, mock-inoculated tissues were sampled at the same site as the inoculated samples at each time point. Samples were frozen in liquid nitrogen immediately after collection. The whole assay was repeated once, with two trays per replicate, 10 seedlings per tray. Plant tissue samples collected from all the trays per treatment were pooled for each biological replicate. RNA preparation, cDNA synthesis, and qPCR procedures were as described in [10], except the SuperScript ${ }^{\circledR}$ III First-Strand Synthesis System was used instead (Invitrogen Inc., Carlsbad, CA). The same house-keeping genes used in [10] were used in this study: a putative ubiquitin gene (Gma.441.1.S1_at) and a putative F-box protein (Gma.6079.1.S1_at). Nineteen candidate genes from the QTL 19-1 and 19-2 regions were selected based on their annotated functions, sequence variation between $\mathrm{R}$ and S, and available microarray data [10,22]. PCR efficiency (E) of each primer pairs can be estimated from standard curves with the equation $(1+\mathrm{E})=10^{(-1 / \text { slope })}$ [87]. Levels of transcript abundance were calculated using the equation $(1+E)^{(-\Delta C t)}$, where $\Delta C t$ equaled the value when the average $\mathrm{Ct}$ value of the reference genes was subtracted from the $\mathrm{Ct}$ value of target gene. Infection response of a target gene was represented by the transcript level fold differences in inoculated (i) samples relative to mock (m) controls, which was calculated from the equation: $\left(1+\mathrm{E}_{\text {gene }}\right)^{\wedge}\left(\mathrm{C}_{\mathrm{Tm}}-\mathrm{C}_{\mathrm{Ti}}\right) / \operatorname{Avg}\left(\left(1+\mathrm{E}_{\mathrm{ref}}\right)^{\wedge}\left(\mathrm{C}_{\mathrm{Tm}}-\mathrm{C}_{\mathrm{Ti}}\right)\right)$, where ref indicated a house keeping gene and Avg was the average of two house-keeping genes. Contrasts of LSMeans were performed among the six soybean lines, or between the three lines with the $\mathrm{R}$ haplotype ( $\mathrm{R}$ group) and those with the $\mathrm{S}$ haplotype (S group) for three types of comparisons (SAS 9.2, SAS Institute Inc. Cary, NC): 1) infection response; 2) transcript abundance at mockinoculated samples; and 3) transcript abundance at inoculated samples. The significant differences of these comparisons were determined by: 1) $P<0.05$; 2) fold difference $>1.5$.

\section{Additional files}

Additional file 1: Genes underlying QTL 19-1 with predicted
functions and microarray data.
Additional file 2: Genes underlying QTL 19-2 with predicted
functions and microarray data.
Additional file 3: SNPs detected between Conrad and Sloan in
sequenced genes underlying QTL 19-1 and 19-2.
Additional file 4: Sequence polymorphisms in Conrad (C) in
comparison to Williams82 (W) and Sloan (S) in Glyma19g41420 and
Glyma19g41800, respectively.

Competing interests

The authors declare that they have no competing interests.

\section{Authors' contributions}

$H W, A W$, and AED conceived and designed the experiments; HW and SL performed the experiments; LMCH contributed to marker selection and mapping analysis; SKSt.M developed populations; HW, AW, SW contributed to analysis; HW, CT, LMCH, and AD wrote the article. All authors read and approved the final manuscript.

\section{Acknowledgements}

We would like to thank S. Berry, M. Ellis, M. Ortega, Z. Zhang, L. Zelaya, C. Phelan, C. Van Pelt, and D. Anco for technical assistance. We thank the OARDC Molecular Cellular Imaging Center for assistance in sequencing. Salaries and research support provided in part by State and Federal Funds appropriated to the Ohio Agricultural Research and Development Center, The Ohio State University. This project was funded in part by NSF Plant Genome grant DBI-0211863, by the United Soybean Board, North Central Soybean Research Program, and by the Ohio's Soybean Producers' check-off dollars through the Ohio Soybean Council. Additional funding was also provided for SNP genotyping from Ohio Bioproducts Innovation Center and an OARDC Seeds grant.

\section{Author details}

${ }^{1}$ The Department of Plant Pathology, The Ohio State University, Wooster OH 44691, USA. ${ }^{2}$ Molecular and Cellular Imaging Center, OARDC, Wooster $\mathrm{OH}$ 44691, USA. ${ }^{3}$ Department of Horticulture and Crop Science, The Ohio State University, Columbus $\mathrm{OH}$ 43210, USA

Received: 7 April 2012 Accepted: 14 August 2012

Published: 28 August 2012

\section{References}

1. Grau CR, Dorrance AE, Bond J, Russin JS: Fungal Diseases. In Soybeans: Improvement, Production and Uses. Edited by Boerma HR, Specht JE. Madison, WI: American Society of Agronomy; Crop Science Society of America; Soil Science Society of America; 2004.

2. Schmitthenner AF: Problems and progress in control of Phytophthora root rot of soybean. Plant Dis 1985, 69:362-368.

3. Enkerli $\mathrm{K}$, Hahn MG, Mims CW: Ultrastructure of compatible and incompatible interactions of soybean roots infected with the plant pathogenic oomycete Phytophthora sojae. Can J Bot 1997, 75:1493-1508.

4. Mideros S: Study of incomplete resistance to Phytophthora sojae in soybean, MSc Thesis.: The Ohio State University, Plant Pathology; 2006.

5. Ranathunge $K$, Thomas RH, Fang X, Peterson CA, Gijzen M, Bernards MA: Soybean root suberin and partial resistance to root rot caused by Phytophthora sojae. Phytopathology 2008, 98:1179-1189.

6. Burnham KD, Dorrance AE, Van Toai TT, St Martin SK: Quantitative trait loci for partial resistance to Phytophthora sojae in soybean. Crop Sci 2003, 43:1610-1617

7. Han Y, Teng W, Yu K, Poysa V, Anderson T, Qiu L, Lightfoot DA, Li W: Mapping QTL tolerance to Phytophthora root rot in soybean using 
microsatellite and RAPD/SCAR derived markers. Euphytica 2008, 162:231-239.

8. Li X, Han Y, Teng W, Zhang S, Yu K, Poysa V, Anderson T, Ding J, Li W: Pyramided QTL underlying tolerance to Phytophthora root rot in megaenvironments from soybean cultivars 'Conrad' and 'Hefeng 25'. Theor Appl Genet 2010, 121:651-658.

9. Tucker DM, Saghai Maroof MA, Mideros S, Skoneczka JA, Nabati DA, Buss GR, Hoeschele I, Tyler BM, St Martin SK, Dorrance AE: Mapping quantitative trait loci for partial resistance to Phytophthora sojae in a soybean interspecific cross. Crop Sci 2010, 50:628-635.

10. Wang H, Waller L, Tripathy S, St Martin SK, Zhou L, Krampis K, Tucker DM, Mao Y, Hoeschele I, Saghai Maroof MA, Tyler BM, Dorrance AE: Analysis of genes underlying soybean quantitative trait loci conferring partial resistance to Phytophthora sojae. The Plant Genome 2010 3:23-40

11. Wang H, St Martin SK, Dorrance AE: Comparison of phenotypic methods and yield contributions of QTL for partial resistance to Phytophthora sojae in soybean. Crop Sci 2012, 52:609-622

12. Weng C, Yu K, Anderson TR, Poysa V: A quantitative trait locus influencing tolerance to Phytophthora root rot in the soybean cultivar Conrad. Euphytica 2007, 158:81-86.

13. Wu X, Zhou B, Zhao J, Guo N, Zhang B, Yang F, Chen S, Gai J, Xing H: Identification of quantitative trait loci for partial resistance to Phytophthora sojae in soybean. Plant Breeding 2011, 130:144-149.

14. Kou Y, Wang S: Broad-spectrum and durability: understanding of quantitative disease resistance. Curr Opin Plant Biol 2010, 13:181-185.

15. St Clair DA: Quantitative disease resistance and quantitative resistance loci in breeding. Annu Rev Phytopathol 2010, 48:247-268

16. Poland JA, Balint-Kurti PJ, Wisser RJ, Pratt RC, Nelson RJ: Shades of gray: the world of quantitative disease resistance. Trends Plant Sci 2009, 14:1360-1385.

17. Young ND: QTL mapping and quantitative disease resistance in plants. Annu Rev Phytopathol 1996, 34:479-501.

18. Vega-Sáncheza ME, Redinbaugh MG, Costanzo S, Dorrance AE: Spatial and temporal expression analysis of defense-related genes in soybean cultivars with different levels of partial resistance to Phytophthora sojae. Physiol Mol Plant Pathol 2005, 66:175-182

19. Thomas R, Fang X, Ranathunge K, Anderson TR, Peterson CA, Bernards MA: Soybean root suberin: anatomical distribution, chemical composition, and relationship to partial resistance to Phytophthora sojae. Plant Physiol 2007, 144:299-311.

20. Tyler BM, Jiang RHY, Zhou L, Tripathy S, Dou D, Torto-Alalibo T, Li H, Mao Y, Liu B, Vega-Sanchez M, Mideros SX, Hanlon R, Smith BM, Krampis K, Ye K, St Martin S, Dorrance AE, Hoeschele I, Saghai Maroof MA: Functional genomics and bioinformatics of the Phytophthora sojae-soybean interaction. In Genomics of Disease. Edited by Gustafson JP, Taylor J, Stacey G. New York: Springer; 2007.

21. Waller L, Zhou L, Mideros SX, Tripathy S, Mao Y, Hanlon R, Torto-Alalibo T, St Martin SK, Saghai Maroof MA, Hoeschele I, Dorrance AE, Tyler BM: Transcriptional profiling of potential regulatory factors modulating defense mechanisms in soybean under $P$. sojae infection. In The 8th International Conference on Systems Biology: 1-6 Oct. 2007. Long Beach, California; 2007:H45

22. Zhou L, Mideros S, Bao L, Hanlon R, Arredondo FD, Tripathy S, Krampis K Jerauld A, Evans C, St Martin SK, Saghai Maroof MA, Hoeschele I, Dorrance $A E$, Tyler BM: Infection and genotype remodel the entire soybean transcriptome. BMC Genomics 2009, 10:49.

23. Schmutz J, Cannon SB, Schlueter J, Ma J, Mitros T, Nelson W, Hyten DL, Song Q, Thelen JJ, Cheng J, Xu D, Hellsten U, May GD, Yu Y, Sakurai T, Umezawa T, Bhattacharyya MK, Sandhu D, Valliyodan B, Lindquist E, Peto M, Grant D, Shu S, Goodstein D, Barry K, Futrell-Griggs M, Abernathy B, Du J, Tian Z, Zhu L, et al: Genome sequence of the paleopolyploid soybean. Nature 2010, 463:178-183.

24. Fukuoka S, Okuno K: QTL analysis and mapping of pi21, a recessive gene for field resistance to rice blast in Japanese upland rice. Theor Appl Genet 2001, 103:185-190.

25. Fukuoka S, Saka N, Koga H, Ono K, Shimizu T, Ebana K, Hayashi N, Takahashi A, Hirochika H, Okuno K, Yano M: Loss of function of a proline-containing protein confers durable disease resistance in rice. Science 2009, 325:998-1001.
26. Fu D, Uauy C, Distelfeld A, Blechl A, Epstein L, Chen X, Sela H, Fahima T, Dubcovsky J: A kinase START gene confers temperature dependent resistance to wheat stripe rust. Science 2009, 323:1357-1360.

27. Krattinger SG, Lagudah ES, Spielmeyer W, Singh RP, Huerta-Espino J, McFadden $H$, Bossolini E, Selter LL, Keller B: A putative ABC transporter confers durable resistance to multiple fungal pathogens in wheat. Science 2009, 323:1360-1363.

28. Spielmeyer W, Singh RP, McFadden H, Wellings CR, Huerta-Espino J, Kong X Appels R, Lagudah ES: Fine scale genetic and physical mapping using interstitial deletion mutants of $L r 34 / Y r 18$ : a disease resistance locus effective against multiple pathogens in wheat. Theor App/ Genet 2008, 116:481-490.

29. Stroup WW: Why mixed models in applications of mixed models in agriculture and related disciplines. Baton Rouge, LA: Southern Coop Ser Bull. Louisiana Agricultural Experiment Station; 1989.

30. Demirbas A, Rector BG, Lohnes DG, Fioritto RJ, Graef GL, Cregan PB, Shoemaker RC, Specht JE: Simple sequence repeat markers linked to the soybean Rps genes for Phytophthora resistance. Crop Sci 2001, 41:1220-1222.

31. Sandhu D, Gao H, Cianzio S, Bhattacharyya MK: Deletion of a disease resistance nucleotide-binding-site leucine-rich-repeat-like sequence is associated with the loss of the Phytophthora resistance gene Rps4 in soybean. Genetics 2004, 168:2157-2167.

32. Grant D, Nelson RT, Cannon SB, Shoemaker RC: SoyBase, the USDA-ARS soybean genetics and genomics database. Nucleic Acids Res 2010, 38: D843-D846.

33. Hyten DL, Choi IY, Song Q, Specht JE, Carter TE, Shoemaker RC, Hwang EY, Matukumalli LK, Cregan PB: A high density integrated genetic linkage map of soybean and the development of a 1536 universal soy linkage panel for quantitative trait locus mapping. Crop Sci 2010, 50:960-968.

34. Deschamps S, la Rota M, Ratashak JP, Biddle P, Thureen D, Farmer A, Luck S, Beatty M, Nagasawa N, Michael L, Llaca V, Sakai H, May G, Lightner J, Campbell MA: Rapid genome-wide single nucleotide polymorphism discovery in soybean and rice via deep resequencing of reduced representation libraries with the Illumina genome analyzer. The Plant Genome 2009, 3:53-68.

35. Choi IY, Hyten DL, Matukumalli LK, Song Q, Chaky JM, Quigley CV, Chase K, Lark KG, Reiter RS, Yoon MS, Hwang EY, Yi SI, Young ND, Shoemaker RC, Van Tassel CP, Specht JE, Cregan PB: A soybean transcript map: Gene distribution, haplotype and single-nucleotide polymorphism analysis. Genetics 2007, 176:685-696.

36. Zhu YL, Song QJ, Hyten DL, Van Tassell CP, Matukumalli LK, Grimm DR Hyatt SM, Fickus EW, Young ND, Cregan PB: Single-nucleotide polymorphisms in soybean. Genetics 2003, 163:1123-1134

37. Gaudet M, Fara AG, Sabatti M, Kuzminsky E, Mugnozza GS: Single-reaction for SNP genotyping on agarose gel by allele-specific PCR in black poplar (Populus nigra L.). Plant Mol Biol Rep 2007, 25:1-9.

38. Dodd AN, Kudla J, Sanders D: The language of calcium signaling. Annu Rev Plant Biol 2010, 61:593-620.

39. Guo Y, Xiong L, Song CP, Gong D, Halfter U, Zhu JK: A calcium sensor and its interacting protein kinase are global regulators of abscisic acid signaling in Arabidopsis. Dev Cell 2002, 3:233-244.

40. Pandey GK, Cheong YH, Kim KN, Grant JJ, Li L, Hung W, D'Angelo C, Weinl S, Kudla J, Luan S: The calcium sensor calcineurin B-like 9 modulates abscisic acid sensitivity and biosynthesis in Arabidopsis. Plant Cell 2004, 16:1912-1924.

41. McDonald KL, Cahill DM: Influence of abscisic acid and the abscisic acid biosynthesis inhibitor, norflurazon, on interactions between Phytophthora sojae and soybean (Glycine max). Eur J Plant Pathol 1999 105:651-658.

42. Ward EW, Cahill DM, Bhattacharyya MK: Abscisic acid suppression of phenylalanine ammonialyase activity and mRNA, and resistance of soybeans to Phytophthora megasperma f.sp. glycinea. Plant Physiol 1989, 91:23-27.

43. Kovtun Y, Chiu W, Tena G, Sheen J: Functional analysis of oxidative stressactivated mitogen-activated protein kinase cascade in plants. Proc Natl Acad Sci USA 2000, 97:2940-2945

44. Suarez Rodriguez MS, Petersen M, Mundy J: Mitogen-activated protein kinase signaling in plants. Annu Rev Plant Biol 2010, 61:621-649.

45. Diaz M, Achkor H, Titarenko E, Martinez MC: The gene encoding glutathione-dependent formaldehyde dehydrogenase/GSNO reductase 
is responsive to wounding, jasmonic acid and salicylic acid. FEBS (Fed Eur Bio-chem Soc) Lett 2003, 543:136-139.

46. Feechan A, Kwon E, Yun BW, Wang Y, Pallas JA, Loake GJ: A central role for S-nitrosothiols in plant disease resistance. Proc Natl Acad Sci USA 2005, 102:8054-8059.

47. Moreau M, Lindermayr C, Durner J, Klessig DF: NO synthesis and signaling in plants-where do we stand? Physiol Plant 2010, 138:372-383.

48. Rusterucci C, Espunya MC, Diaz M, Chabannes M, Martinez MC: Snitrosoglutathione reductase affords protection against pathogens in Arabidopsis, both locally and systemically. Plant Physiol 2007. 143:1282-1292.

49. Pearce G, Moura DS, Stratmann J, Ryan CA: RALF, a 5-kDa ubiquitous polypeptide in plants, arrests root growth and development. Proc Natl Acad Sci USA 2001, 98:12843-12847.

50. Gupta S, Chakraborti D, Sengupta A, Basu D, Das S: Primary metabolism of chickpea is the initial target of wound inducing early sensed Fusarium oxysporum f. sp. ciceri Race I. PLoS One 2010, 5:e9030.

51. Haruta M, Constabel CP: Rapid Alkalinization Factors in Poplar Cell Cultures. Peptide Isolation, cDNA Cloning, and Differential Expression in Leaves and Methyl Jasmonate-Treated Cells. Plant Physio/ 2003, 131:814-823.

52. Tian ZD, Liu J, Wang BL, Xie CH: Screening and expression analysis of Phytophthora infestans induced genes in potato leaves with horizontal resistance. Plant Cell Rep 2006, 25:1094-1103.

53. Narusaka $Y$, Narusaka M, Park $P$, Kubo $Y$, Hirayama T, Seki M, Shiraishi $T$, Ishida J, Nakashima M, Enju A, Sakurai T, Satou M, Kobayashi M, Shinozaki K: $\mathrm{RCH1}$, a locus in Arabidopsis that confers resistance to the hemibiotrophic fungal pathogen Colletotrichum higginsianum. Mol Plant Microbe Interact 2004, 17:749-762.

54. Domingo C, Andrés F, Tharreau D, Iglesias DJ, Talón M: Constitutive expression of OsGH3.1 reduces auxin content and enhances defense response and resistance to a fungal pathogen in rice. Mol Plant Microbe Interact 2009, 22:201-210.

55. Kidd BN, Kadoo NY, Dombrecht B, Tekeoglu M, Gardiner DM, Thatcher LF, Aitken EA, Schenk PM, Manners JM, Kazan K: Auxin signaling and transport promote susceptibility to the root-infecting fungal pathogen Fusarium oxysporum in Arabidopsis. Mol Plant Microbe Interact 2011, 24:733-748.

56. Wang D, Pajerowska-Mukhtar K, Culler AH, Dong X: Salicylic acid inhibits pathogen growth in plants through repression of the auxin signaling pathway. Curr Biol 2007, 17:1784-1790.

57. Navarro L, Dunoyer P, Jay F, Arnold B, Dharmasiri N, Estelle M, Voinnet O, Jones JDG: Plant miRNA contributes to antibacterial resistance by repressing auxin signaling. Science 2006, 312:436-439.

58. Dombrecht B, Xue GP, Sprague SJ, Kirkegaard JA, Ross JJ, Reid JB, Fitt GP Sweelam N, Schenk PM, Manners JM, Kazan K: MYC2 differentially modulates diverse jasmonate-dependent functions in Arabidopsis. Plant Cell 2007, 19:2225-2245.

59. Pieterse CMJ, Leon-Reyes A, Van der Ent S, Van Wees SCM: Networking by small-molecules hormones in plant immunity. Nat Chem Biol 2009, 5:308-316.

60. Robert-Seilaniantz A, Grant M, Jones JDG: Hormone crosstalk in plant disease and defense: More than just jasmonate salicylate antagonism. Annu Rev Phytopathol 2011, 49:317-343.

61. Minic Z: Physiological roles of plant glycoside hydrolases. Planta 2008, 227:723-740.

62. Smith CJ, Watson CF, Morris PC, Bird CR, Seymour GB, Gray JE, Arnold C, Tucker GA, Schuch W, Harding S, Grierson D: Inheritance and effect on ripening of antisense polygalacturonase genes in transgenic tomatoes. Plant Mol Biol 1990, 14:369-379.

63. Smith CJS, Watson CF, Ray J, Bird CR, Morris PC, Schuch W, Grierson D: Antisense RNA inhibition of polygalacturonase gene expression in transgenic tomatoes. Nature 1998, 334:724-726.

64. Walton JD: Deconstructing the cell wall. Plant Physio/ 1994, 104:1113-1118.

65. Herron SR, Benen JAE, Scavetta RD, Visser J, Jurnak F: Structure and function of pectic enzymes: Virulence factors of plant pathogens. Proc Natl Acad Sci USA 2000, 97:8762-8769.

66. Reignault $P$, Valette-Collet $O$, Boccara $M$ : The importance of fungal pectinolytic enzymes in plant invasion, host adaptability and symptom type. Eur J Plant Pathol 2008, 120:1-11.

67. Lee YJ, Liu B: Cytoskeletal motors in Arabidopsis: Sixty-one kinesins and seventeen myosins. Plant Physiol 2004, 136:3877-3883.
68. Schmidt SM, Panstruga R: Cytoskeleton functions in plant-microbe interactions. Physiol Mol Plant Pathol 2007, 71:135-148.

69. Chrispeels MJ, Raikhel NV: Lectins, lectin genes and their role in plant defense. Plant Cell 1991, 3:1-9.

70. van Damme EJM, Peumans WJ, Barre A, Rougé P: Plant lectins: A composite of several distinct families of structurally and evolutionary related proteins with diverse biological roles. Crit Rev Plant Sci 1998, 17:575-692.

71. Peumans WJ, van Damme EJM: Lectins as plant defense proteins. Plant Physiol 1995, 109:347-353.

72. Gibson DM, Stack S, Krell K, House J: A comparison of soybean agglutinin in cultivars resistant and susceptible to Phytophthora megasperma var. sojae (race 1). Plant Physiol 1982, 70:560-566.

73. Dannenhoffer JM, Schulz A, Skaggs MI, Bostwick DE, Thompson GA: Expression of the phloem lectin is developmentally linked to vascular differentiation in cucurbits. Planta 1997, 201:405-414.

74. Balachandran S, Xiang Y, Schobert C, Thompson GA, Lucas WJ: Phloem sap proteins from Cucurbita maxima and Ricinus communis have the capacity to traffic cell to cell through plasmodesmata. Proc Natl Acad Sci USA 1997, 94:14150-14155.

75. Trujillo M, Shirasu K: Ubiquitination in plant immunity. Curr Opinion in Plant Biol 2010, 13:402-408.

76. Craig A, Ewan R, Mesmar J, Gudipati V, Sadanandom A: E3 ubiquitin ligases and plant innate immunity. J Exp Bot 2009, 60:1123-1132.

77. Lee SJ, Rose JKC: Mediation of the transition from biotrophy to necrotrophy in hemibiotrophic plant pathogens by secreted effector proteins. Plant Signal Behav 2010, 5:769-772.

78. Manosalva PM, Davidson RM, Liu B, Zhu X, Hulbert SH, Leung H, Leach JE: A germin-like protein gene family functions as a complex quantitative trait locus conferring broad-spectrum disease resistance in rice. Plant Physiol 2009, 149:286-296.

79. Dorrance AE, Berry SA, Anderson TR, Meharg C: Isolation, storage, pathotype characterization, and evaluation of resistance for Phytophthora sojae in soybean. Plant Health Progress 2008, 10.1094/PHP-2008-0118-01-DG.

80. Song Q, Jia G, Zhu Y, Grant D, Nelson RT, Hwang EY, Hyten DL, Cregan P: Abundance of SSR motifs and development of candidate polymorphic SSR markers (BARCSOYSSR_1.0) in soybean. Crop Sci 2010, 50:1950-1960.

81. Van Ooijen JW: JoinMap ${ }^{\circledR} 4.0$, Software for the calculation of genetic linkage maps in experimental populations. The Netherlands: Kyazma B.V, Wageningen; 2006.

82. Van Ooijen JW: MapQTL 5, Software for the mapping of quantitative trait loci in experimental populations. The Netherlands: Kyazma BV, Wageningen; 2004

83. Churchill GA, Doerge RW: Empirical threshold values for quantitative trait mapping. Genetics 1994, 138:963-971.

84. Calla B, Vuong T, Radwan O, Hartman GL, Clough SJ: Gene expression profiling soybean stem tissue early response to Sclerotinia sclerotiorum and in silico mapping in relation to resistance markers. Plant Genome 2009, 2:149-166.

85. You FM, Huo N, Gu YQ, Luo M, Ma Y, Hane D, Lazo GR, Dvorak J, Anderson OD: BatchPrimer3: A high throughput web application for PCR and sequencing primer design. BMC Bioinforma 2008, 9:253.

86. Harismendy O, Frazer K: Method for improving sequence coverage uniformity of targeted genomic intervals amplified by LR-PCR using Illumina GA sequencing-by-synthesis technology. Biotechniques 2009, 46:229-231

87. Pfaffl MW: A new mathematical model for relative quantification in realtime RT-PCR. Nucleic Acids Res 2001, 29:e45.

doi:10.1186/1471-2164-13-428

Cite this article as: Wang et al:: Dissection of two soybean QTL conferring partial resistance to Phytophthora sojae through sequence and gene expression analysis. BMC Genomics 2012 13:428. 